\title{
Atropisomerism in Styrene: Synthesis, Stability, and Applications
}

\author{
Jia Feng ${ }^{a}$ \\ Zhenhua Gu*a,b (D) \\ a Department of Chemistry and Hefei National Laboratory for \\ Physical Sciences at the Microscale, University of Science and \\ Technology of China, 96 Jinzhai Road, Hefei, Anhui 230026, \\ P. R. of China \\ zhgu@ustc.edu.cn \\ b Ocean College, Minjiang University, Fuzhou, Fujian 350108, \\ P. R. of China
}

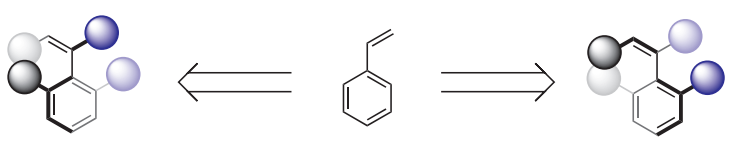

Received: 25.01 .2021

Accepted after revision: 02.02.2021

Published online: 10.03 .2021

DOI: 10.1055/s-0040-1706028; Art ID: so-2021-d0005-r

License terms: (c) $($ () $(9)$

(c) 2021. The Author(s). This is an open access article published by Thieme under the terms of the Creative Commons Attribution-NonDerivative-NonCommercial-License, permitting copying and reproduction so long as the original work is given appropriate credit. Contents may not be used for commercial purposes or adapted, remixed, transformed or built upon. (https://creativecommons.org/licenses/by-nc-nd/4.0/)

Abstract Atropisomeric styrenes are a class of optically active compounds, the chirality of which results from restricted rotation of the $C($ vinyl) $-C($ aryl) single bond. In comparison with biaryl atropisomers, the less rigid skeleton of styrenes usually leads them to have lower rotational barriers. Although it has been overlooked for a long time, scientists have paid attention to this class of unique molecules in recent years and have developed many methods for the preparation of optically active atropisomeric styrenes. In this article, we review the development of the concept of atropisomeric styrenes, along with their isolation, asymmetric synthesis, and synthetic applications.

1 Introduction

The Concept of Styrene Atropisomerism

Early Research: Separation of Optically Active Styrenes

Synthesis of Optically Active Styrenes

Stability of the Chirality of Atropisomeric Styrenes

Outlook

Key words atropisomers, styrene, axial chirality, asymmetric synthesis, asymmetric $\mathrm{C}-\mathrm{H}$ functionalization

\section{Introduction}

Atropisomerism arises from restricted rotation around a single bond as a result of the steric hindrance of adjacent moieties, ring strain, or other structural factors. It is an important way for chiral molecules bearing no stereogenic centers to demonstrate three-dimensional character. As representative atropisomers, biaryls occur widely in bioac- tive molecules, medicines, and materials science. ${ }^{1}$ Atropisomeric biaryls are also a prominent scaffold and have been widely studied because of their stable chiral axis and divergent applications in asymmetric synthesis. In contrast, atropisomeric styrenes have been overlooked for a half century as a result of the perceived 'poor stability' of the chiral axis located in the $\mathrm{C}_{\mathrm{sp} 2}-\mathrm{C}_{\mathrm{sp} 2}$ bond between the vinyl and aryl groups. This review summarizes the early studies of atropisomeric styrenes, including their discovery, resolution, and synthesis, as well as the recent developments in catalytic asymmetric synthesis. Compounds showing significant aromaticity, such as atropisomeric 4-aryl isoquinolin$1(2 \mathrm{H})$-ones, are not discussed here because they are more akin to biaryl atropisomers. ${ }^{2}$

\section{The Concept of Styrene Atropisomerism}

It is generally accepted that the stability of biaryl axial chirality originates from the characteristics of the axis and the steric hindrance of groups adjacent to the axis. For styrene derivatives, prevention of free rotation around the axis connecting the vinyl and aryl groups is much harder and needs more sterically hindered substituents. It is clear that styrenes are generally less rigid than biaryls, resulting in the rotational barriers of styrenes being lower than the corresponding barriers of biaryls. As early as 1928, Hyde and Adams ${ }^{3}$ stated that 'The molecules (1) would undoubtedly be less rigid, but if the free rotation around the bond joining the unsaturated linkage to the substituted ring is prevented, any position of the olefin or carbonyl group and the unsubstituted ring in space should give an asymmetric molecule.' This was the first time that chemists predicted the possibility of axial chirality existing in styrene compounds. 


\section{Early Research: Separation of Optically Active Styrenes}

In 1930, the attempt of Maxwell and Adams ${ }^{4}$ to separate the enantiomers of styrenes $\mathbf{2}, \mathbf{3}$, and $\mathbf{4}$ by resolution ended with failure (Scheme 1), with the low steric bulk of the $\alpha$ hydrogen atom of the styrene accounting for the unaccomplished separation. In 1938, Mills and Dazeley ${ }^{5}$ succeeded in synthesizing racemic $o$-( $\beta, \beta$-dimethyl- $\alpha$-isopropylvinyl)phenyltrimethyl ammonium iodide (5) and resolving its isomers, which verified the original postulate about the possibility of stable atropisomerim in styrenes. On replacing the methyl group (with Z-geometry to the aryl ring) with a hydrogen atom to form $\mathbf{6}$, no enantiomers could be separated.

In 1940, Miller and Adams ${ }^{6}$ completed the synthesis of a more sterically hindered styrene, $\beta$-chloro- $\beta$ - $(2,4,6$ trimethyl-3-bromophenyl)- $\alpha$-methylacrylic acid (7), and its enantiomers were successfully resolved. With a chlorine atom at the $\beta$-position of the styrene and a methyl group adjacent to the axis, compound $\mathbf{7}$ demonstrated excellent stability, displaying no decrease in enantiopurity on heating to reflux in ethanol for $15 \mathrm{~h}$ or in glacial acetic acid for $12 \mathrm{~h}$. Bromination of $\mathbf{7}$ afforded the optically inactive symmetric compound $\mathbf{8}$. In contrast, the installation of a sulfonyl group on $\mathbf{7}$ gave the optically active compound $\mathbf{9}$. Later, Adams and co-workers carried out further research into the relevance between structure and atropisomeric stability in styrenes. ${ }^{6,7}$
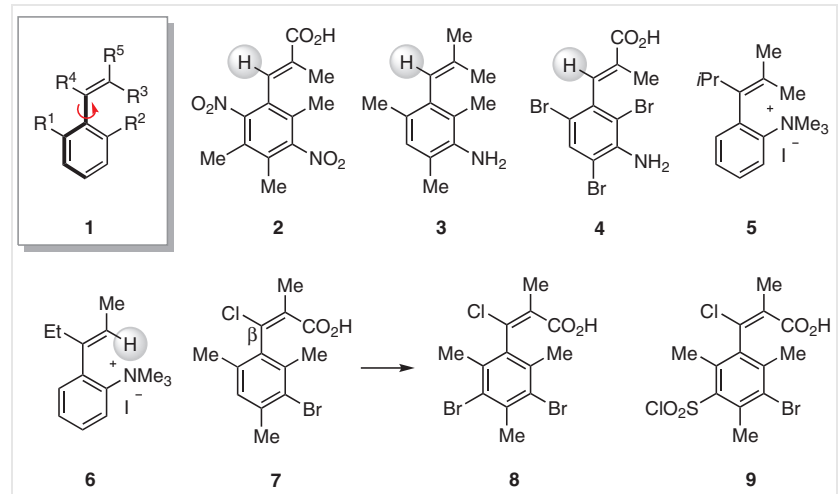

6

7

9

Scheme 1 Atropisomeric styrenes in early studies

Notable retention of partial chirality was observed by Fuji and co-workers in the alkylation reaction of $\mathbf{1 0}$ with a carbon stereogenic center at the $\alpha$-position of a carbonyl group in 1991. ${ }^{8}$ It seemed that the size of the electrophile did not affect the enantioselectivity (Scheme 2, table). The authors carried out rapid HPLC analysis of byproduct 12, which gave a $65 \%$ enantiomeric excess (ee) value. The control experiment indicated that alkylation would form atropisomeric enolate INT-1, which could be attacked by the electrophile to afford the C-alkylation product $\mathbf{1 1}$ and O-alkylation product $\mathbf{1 2}$ with moderate ee values (Scheme 2, bottom).

\section{Biographical Sketches}

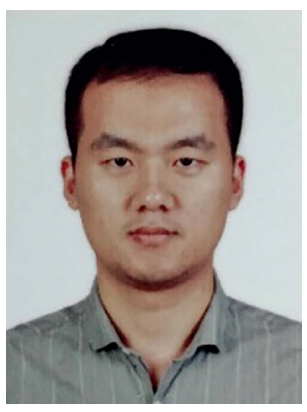

Jia Feng received his Bachelor's degree from Shandong University (P. R. of China) and his PhD from the University of Science and Technology of China (P. R. of China) under the supervision of Professor Zhenhua $\mathrm{Gu}$ in 2018. He is now a postdoctoral researcher in the same group. His research interests include the construction of atropisomeric molecules via novel methodology and the asymmetric synthesis of bioactive molecules.

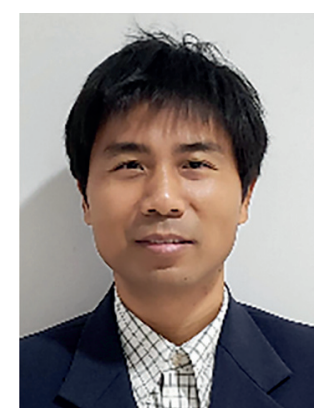

Zhenhua Gu studied chemistry at Nanjing University in 2002, and then he pursued his PhD studies with Professor Shengming Ma at the Shanghai Institute of Organic Chemistry (P. R. of China). He conducted postdoctoral research at the
University of California Berkeley (USA) with Professor K. P. C. Vollhardt and the University of California at Santa Barbara (USA) with Professor A. Zakarian. In 2012, he began his independent academic career at the University of Science and Tech- nology of China (P. R. of China). Research in his group mainly focuses on the development of new methods for asymmetric synthesis, particularly for atropisomers and related natural products. 


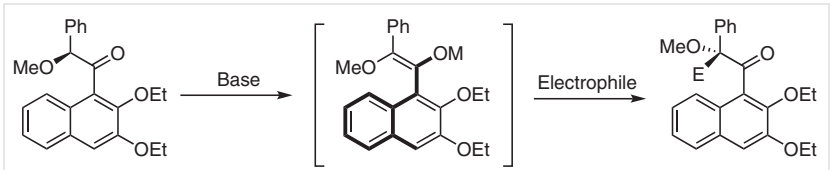

\begin{tabular}{cccc} 
10 $(93 \%$ ee) & \multicolumn{2}{c}{ INT-1 } & $\mathbf{1 1}$ \\
\hline Entry & Electrophile & Yield/\% & ee/\% \\
\hline 1 & Mel & 48 & 66 \\
2 & Etl & 27 & 65 \\
3 & $\mathrm{PhCH}_{2} \mathrm{Br}$ & 31 & 67 \\
4 & $\mathrm{CH}_{2}=\mathrm{CHCH}_{2} \mathrm{Br}$ & 36 & 48 \\
\hline
\end{tabular}

Control experiment:

$10(93 \%$ ee) $\stackrel{\text { Standard conditions }}{\longrightarrow} 11(48 \%, 66 \%$ ee $) \quad+$

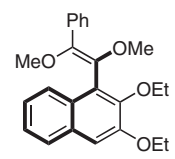

$12(15 \%, 65 \%$ ee $)$

Scheme 2 Enantioselective alkylation via an intermediate atropisoenolate

In 2016, Clayden and co-workers ${ }^{9}$ synthesized a series of 1-aryl-3,4-dihydroisoquinolines 13, which are structural analogs of styrene featuring a potentially atropoisomerically stable axis. They studied the stabilities by calculation of the rotational barrier energies. The data given in Figure 1 show that the stability increased as the size of the adjacent substituted moiety $X$ increased (13a-13f). Nevertheless, the half-life of iodide 13d was too short to separate the enantiomers at ambient temperature.

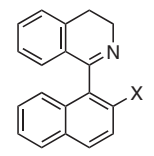

13

\begin{tabular}{cccc}
\hline Compound & $\mathrm{X}$ & $\Delta \mathrm{G}\left(\mathrm{kJ} \mathrm{mol}^{-1}\right)$ & $t_{1 / 2}$ \\
\hline 13a & $\mathrm{H}$ & 54.7 & $10^{-4} \mathrm{~s}$ \\
13b & $\mathrm{Cl}$ & $<90$ & $<5 \mathrm{~min}$ \\
13c & $\mathrm{Br}$ & 92.9 & $15 \mathrm{~min}$ \\
13d & $\mathrm{I}$ & 81.9 & $<1 \mathrm{~min}$ \\
13e & OTf & 103.1 & $36 \mathrm{~d}$ \\
13f & $\mathrm{P}(\mathrm{O}) \mathrm{Ph}_{2}$ & $>>100$ & $>25 \mathrm{~d}$ \\
\hline
\end{tabular}

Figure 1 Substituent effect on the stability of 1-aryl-3,4-dihydroisoquinolines

\section{Synthesis of Optically Active Styrenes}

Given the unique scaffolds of atropisomeric styrenes and their important applications in bioactive molecules and medicines, many approaches to access enantioselective styrenes have been developed during recent decades. In early studies, atropisomeric chirality was constructed from point chirality via chirality transfer. The optically active styrenes could be separated as single distereomers with the aid of chiral auxiliaries. Of all approaches, catalytic asymmetric synthesis comes to the fore because of its high efficiency and divergent functional-group tolerance. Recently, transition-metal-catalyzed cross-couplings, including $\mathrm{C}-\mathrm{H}$ functionalization in a step- and atom-economic manner, have become a powerful method for the preparation of atropoactive styrenes. Furthermore, organo-catalyzed electrophilic addition of vinylidene ortho-quinone methide type intermediates is also an attractive approach.

\subsection{Chirality Transfer Strategy}

In 2001, Miyano, Hattori, and co-workers ${ }^{10}$ reported the synthesis of tertiary alcohol $(R, R)-\mathbf{1 6}$, which was derived from the 1,2-addition of $(R)-\mathbf{1 4}$ and $\mathbf{1 5}$. Compound $\mathbf{1 6}$ was stereospecifically transformed into atropisomeric $(R)-\mathbf{1 7}$ with up to $95 \%$ ee on treatment with $\left(\mathrm{CF}_{3} \mathrm{CO}\right)_{2} \mathrm{O}$ in dichloromethane at room temperature (Scheme 3). Interestingly, the authors found that there was an equilibrium between conformational isomers $\mathbf{1 6} \mathbf{a}$ and $\mathbf{1 6 b}$ observable from the ${ }^{1} \mathrm{H}$ NMR spectrum. The ratio was $1: 5.7$ in $\mathrm{CDCl}_{3}$ but ranged from $1: 1$ to $1: 6.3$ depending on the solvent. The chirality transfer from point to axial chirality can be assumed to occur because of the much lower conversion rate from $\mathbf{1 6 a}$ into $(R)-\mathbf{1 7}$ than the rate from $\mathbf{1 6 b}$ into $(S)-\mathbf{1 7}$.

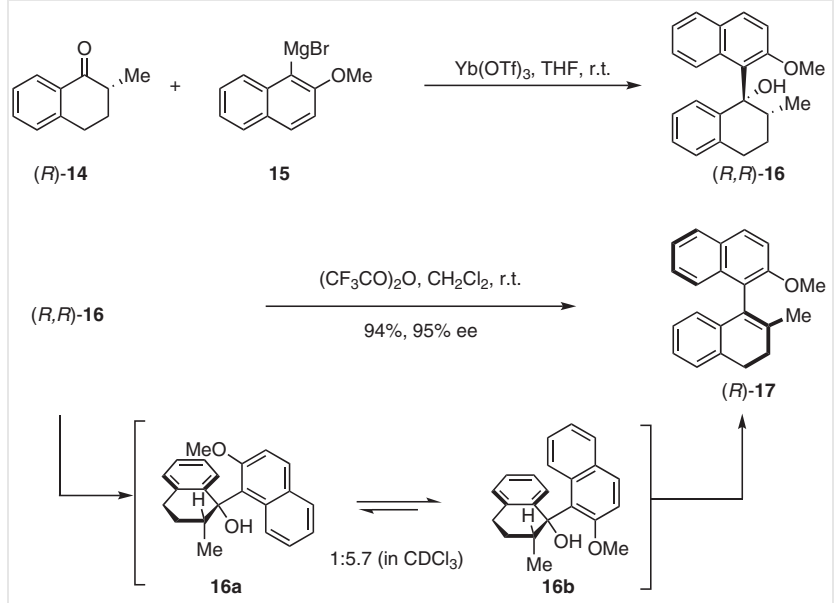

Scheme 3 Synthesis of atroposelective styrenes via chirality transfer

\subsection{Chiral Auxiliary Strategy}

With the assistance of chiral auxiliaries, chiral atropisomeric styrenes can be synthesized in a diastereoselective manner. Subsequent removal of the auxiliary affords the atropisomeric styrenes. In 1996, Baker et al. ${ }^{11}$ disclosed a point to axial chirality transfer via a formal 1,3-hydrogen shift (Scheme 4). Reaction of (1R)-menthyl (R)-(1-p-tolylsulfinyl)-naphthalene-2-carboxylate (18) with indenyllithium delivered major product 19 in $88 \%$ yield and with $59 \%$ diastereoselectivity, together with minor products $\mathbf{2 0}$ and $\mathbf{2 1}$ in a combined yield of $9 \%$ with a ratio of $1: 1$. Esters 20 and 21, with relatively stable axial chirality, were separated by preparative HPLC. The half-life of interconversion between 20 and 21 was about $25 \mathrm{~h}$ in solution at $25^{\circ} \mathrm{C}$. Treatment of isomer 19a (99\% de) with an excess of $\mathrm{LiAlH}_{4}$ afforded carbinol ent-22 in quantitative yield with $98 \%$ ee. A control experiment was performed by quenching the reaction with $\mathrm{DCl}$ in $\mathrm{D}_{2} \mathrm{O}$ within 5 mins and gave ent-22 with 


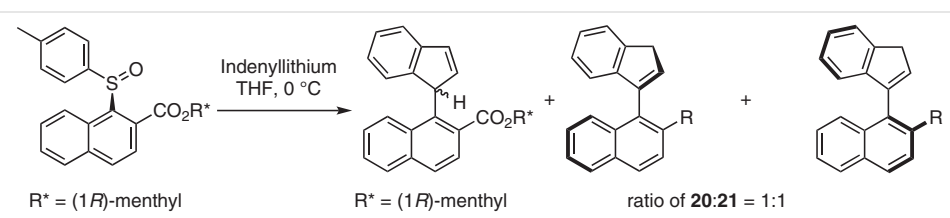

18

19

$20 \mathrm{R}=\mathrm{CO}_{2} \mathrm{R}^{*} \longrightarrow \begin{gathered}\mathrm{LiAlH}_{4} \\ \mathrm{Et}_{2} \mathrm{O}\end{gathered} 22 \mathrm{R}=\mathrm{CH}_{2} \mathrm{OH} \longleftarrow \begin{gathered}21 \mathrm{R}=\mathrm{CO}_{2} \mathrm{R}^{*} \\ 0{ }^{\circ} \mathrm{C}\end{gathered} \longrightarrow$ ent-22 $\mathrm{R}=\mathrm{CH}_{2} \mathrm{OH}$

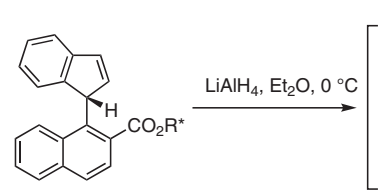

19a

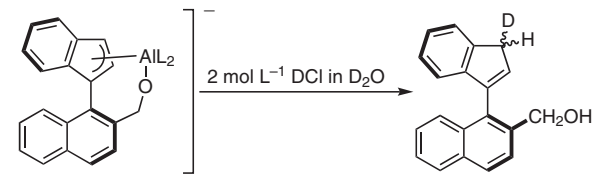

INT-2

ent-22- $d$

Scheme 4 Point to axial chirality transfer strategy

$89 \%$ deuterium incorporation. The authors proposed that the reduction of $19 \mathbf{a}$ with the $S$-conformation at $\mathrm{C}-1$ ' gave ent-22- $d$ via INT-2, on the basis of this labeling experiment.

Diastereoselective synthesis of axial styrenes with the aid of a chiral sulfoxide auxiliary was applied successfully to the stereospecific synthesis of the antibiotic TAN-1085 (23). Suzuki and co-workers ${ }^{12}$ reported an asymmetric synthesis of $\mathbf{2 3}$ through a stereochemical relay strategy featuring a three-step conversion of chirality: central to axial (step A), axial to axial (step B), and axial to central (step C) (Scheme 5). Suzuki-Miyaura coupling of boronic acid 24 and vinyl iodide $\mathbf{2 5}$ containing the chiral sulfoxide auxiliary and subsequent silylation and mono-deprotection of the phenol afforded atropisomeric styrenes 27a and 27b with a diastereoselective ratio of 25:75. Conformation 27b was favored over 27a by the formation of an intramolecular hydrogen bond. Product 27b was separated by flash chromatography on silica gel, and subsequent benzylation gave $\mathbf{2 8}$ in more than $99 \%$ ee, which could be enantioselectively converted into TAN-1085 in a few steps.

Meanwhile, the same group ${ }^{13}$ realized an asymmetric synthesis of atropisomeric styrenes bearing two axial axes via a similar strategy (Scheme 6). Treatment of vinyl iodide 30, featuring a chiral sulfoxide auxiliary, with aryl boric acid 29 furnished atropisomeric styrene $\mathbf{3 1}$ as one diastereomer. After a two-step transformation, 32, bearing two terminal alkenes, was prepared from $\mathbf{3 1}$ and could be selectively converted into planar chiral cyclophane 33 . In a similar procedure, planar chiral cyclophanes 34 and 35, also with the ansa-chain, were readily accessed. The atropisomeric vinyl arene structure also possibly exists in ringstrained macrobiaryl alkenes. ${ }^{14}$

\subsection{Catalytic Asymmetric Synthesis of Atropiso- meric Styrenes}

Benefiting from the rapid development of transitionmetal-catalyzed cross-coupling reactions, many novel and efficient approaches to access atropisomeric styrenes have
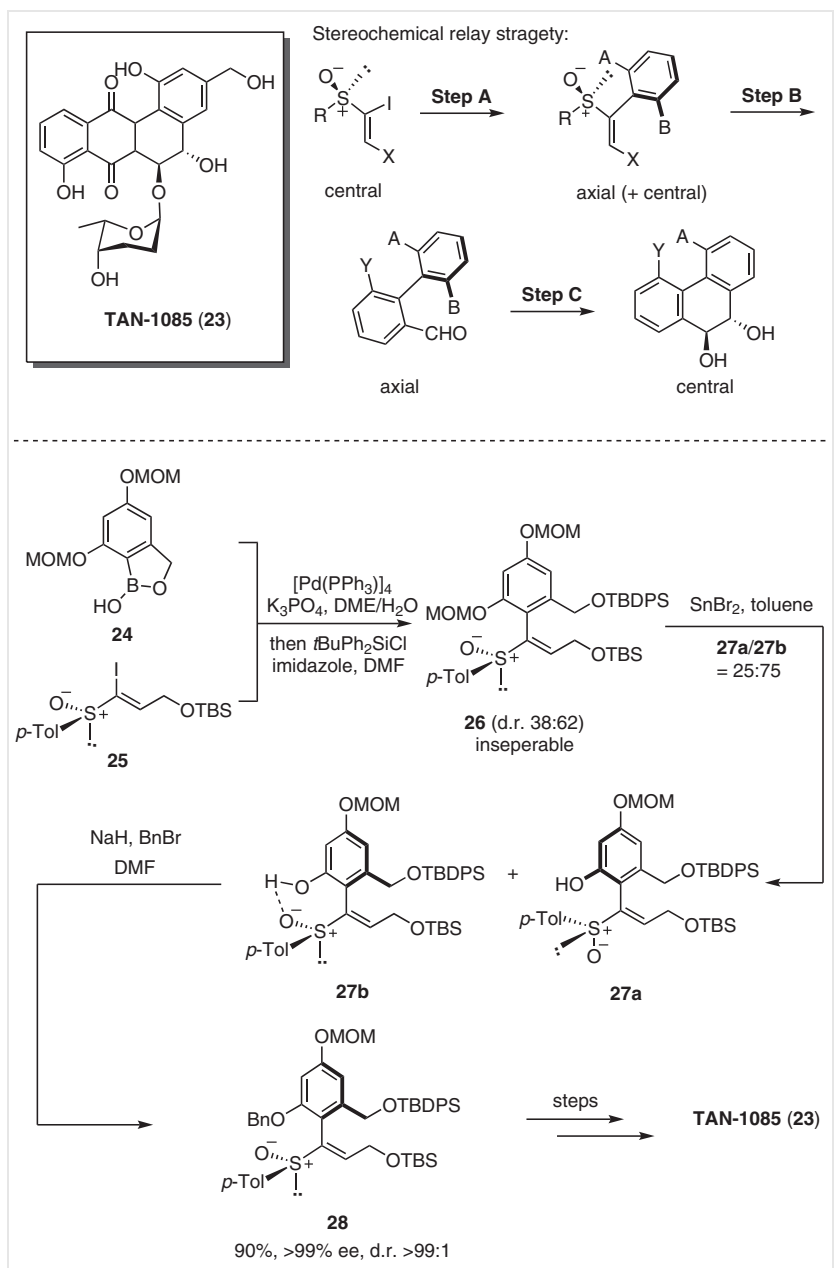

Scheme 5 Asymmetric synthesis of TAN-1085 (23)

been developed. These strategies include the cross-coupling of aryl halides and hydrazones, Suzuki-Miyaura cross-couplings, and cross--coupling reactions via $\mathrm{C}-\mathrm{H}$ activation. 


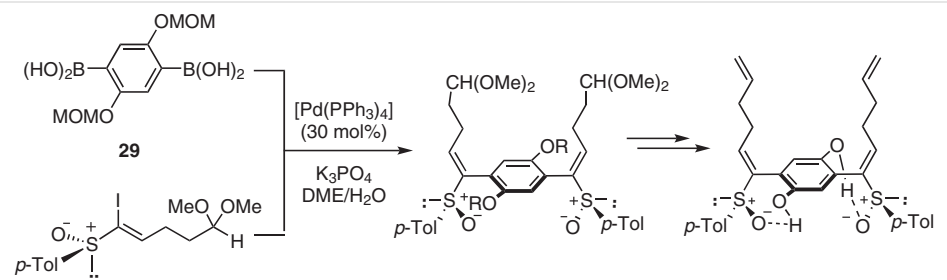

30

31

32
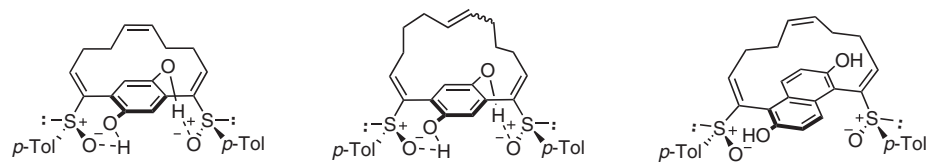

33

34, $E / Z 11: 1$

35

Scheme 6 Synthesis of atropisomeric styrenes with a chiral sulfide auxiliary

It is anticipated that, when styrene structures have the vinyl unit as part of a five- or six-membered ring fused to another aromatic ring, the atropisomerism of these compounds may be more stable than that of acyclic styrenes. For example, dihydro-binaphthalenes and 1-(1H-inden-3$\mathrm{yl})$ naphthalene are supposed to have higher rotational barriers than vinyl naphthalenes.

\subsubsection{Palladium-Catalyzed Cross-Coupling of Aryl Halides And Hydrazones}

In view of the importance of the axial chirality in styrenes, in 2016, Gu and co-workers ${ }^{15}$ developed the first cat- alytic asymmetric synthesis of styrene-type atropisomers (Scheme 7). The protocol with aryl halides $\mathbf{3 6}$ and hydrazones $\mathbf{3 7}$ as standard substrates delivered dihydro-binaphthalenes 38 in up to $99 \%$ yield with up to $97 \%$ ee. The reaction exhibited a broad functional-group tolerance. In the proposed mechanism, the oxidative insertion of $\mathrm{Pd}(0)$ into $\mathbf{3 6}$ gives INT-3, which coordinates with the in situ generated carbene species derived from hydrazone $\mathbf{3 7}$ with the aid of $t \mathrm{BuOLi}$. The newly formed palladium carbene species INT-4 undergoes migration/insertion reactions to produce INT-5, which affords the final product via reductive elimination and liberation of the $\operatorname{Pd}(0)$ catalyst. The chiral styrene was readily oxidized to the atropisomeric biaryl
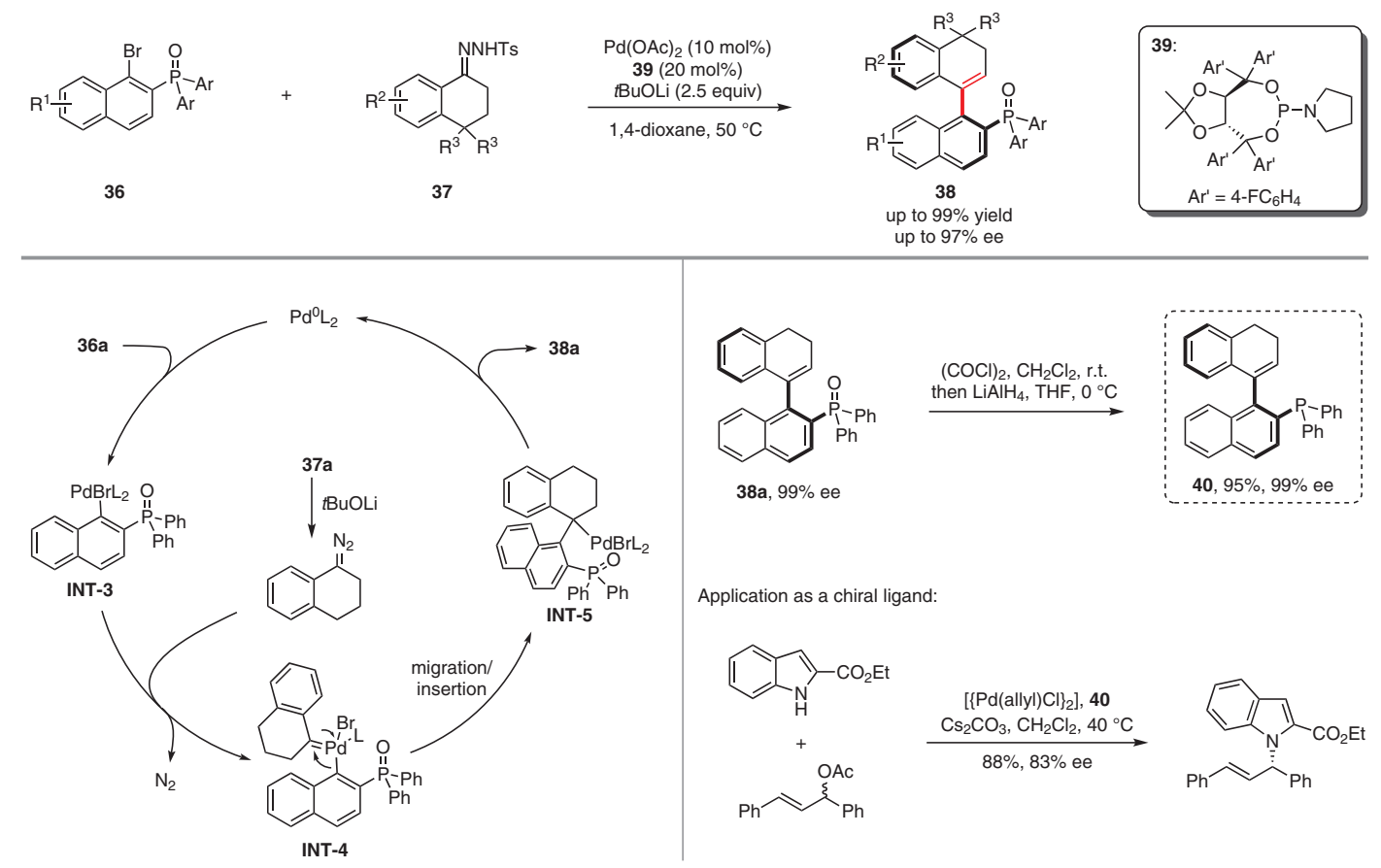

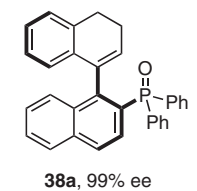

$(\mathrm{COCl})_{2}, \mathrm{CH}_{2} \mathrm{Cl}_{2}$, r.t. then LiAlH 4 , THF, $00^{\circ} \mathrm{C}$

38 a, $99 \%$ ee

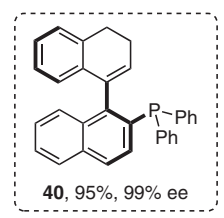

Application as a chiral ligand:
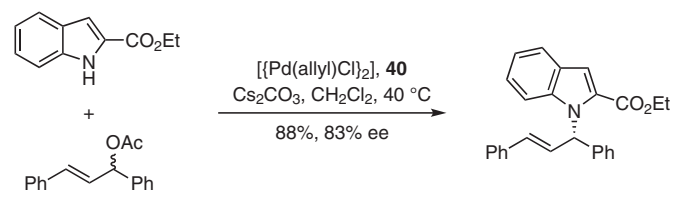

Scheme 7 Carbene strategy for the synthesis of atropisomeric styrenes 
compound without erosion of enantiopurity. Moreover, the $\mathrm{P}(\mathrm{V})$ compound 38a was uneventfully reduced to phosphine 40, which was successfully applied in an asymmetric allylation reaction as an (alkene, phosphine) bidentate ligand.

In further related studies, Wu et al. ${ }^{16}$ employed P-stereogenic bidentate phosphine ligand 44 in the asymmetric synthesis of atropisomeric vinyl arenes with excellent stereocontrol (Scheme 8). In this report, dialkyl phosphonates 41 were compatible substrates, delivering atropisomeric vinyl arenes $\mathbf{4 3}$ with good yields and enantioselectivities. The protocol was successfully applied to the synthesis of atropisomeric compound $\mathbf{4 3 b}$ containing an indene skeleton (86\% ee). For product 43c, with a seven-membered ring, the racemic product was observed. Diphenyl phosphine oxide 38a was synthesized in $75 \%$ yield with $87 \%$ ee, which is slightly lower than the results of $\mathrm{Gu}$ and co-workers. The utility was demonstrated by a gram-scale synthesis of 43e without loss of enantioselectivity. The merit of this work is that dimethyl phosphonate 43a could be further converted into dimethyl phosphine oxide $\mathbf{4 5}$ with methyl magnesium bromide.
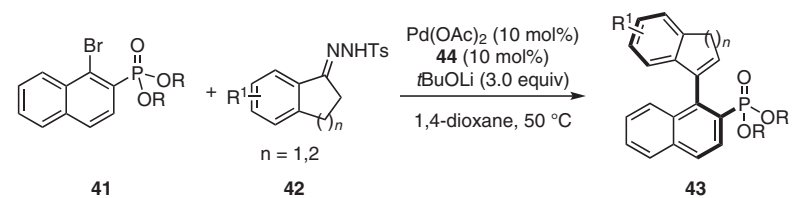

43
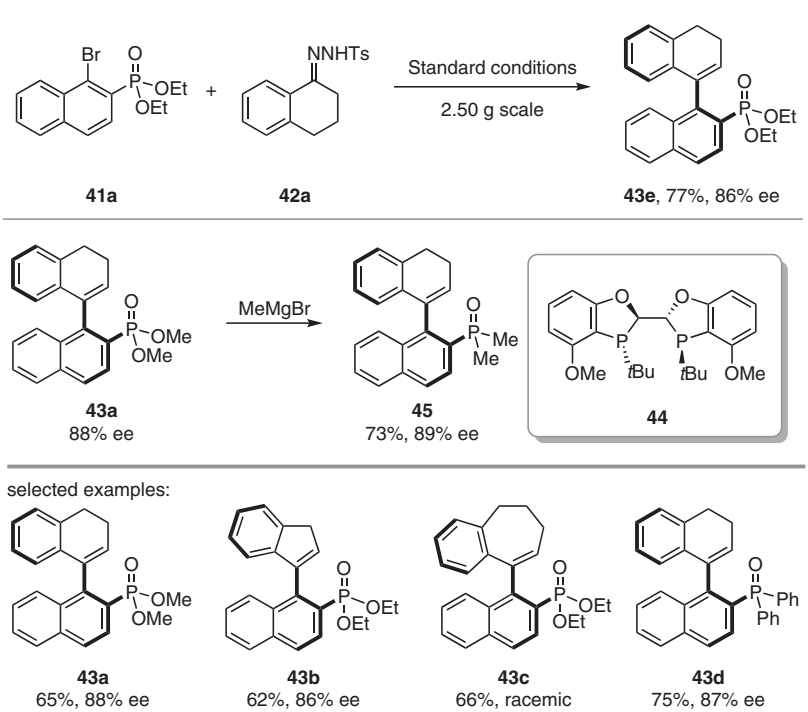

Scheme 8 Palladium-catalyzed atropisomeric styrene synthesis with aryl halides and carbene precursors

\subsubsection{Suzuki-Miyaura Cross-Coupling for Synthesis of 2-Aryl Cyclohex-2-Enone Atropisomers}

In 2017, $\mathrm{Gu}$ and co-workers ${ }^{17}$ disclosed an asymmetric synthesis of 2-aryl cyclohex-2-enone atropisomers 48 via Suzuki-Miyaura coupling of 2-iodo-3-methylcyclohex-2- enones 46 and aryl boronic acids (Scheme 9). BoPhoz 49 exhibited superior stereocontrol over other types of ligand. The advantage of this strategy is that the $\alpha, \beta$-unsaturated ketone displays diverse reactivity in its downstream transformations. Thus, the final products bearing axial chirality, known as 'platform molecules,' could be diversely converted into atropisomeric biaryls. For example, 48a was oxidized into quinone $\mathbf{5 0}$ with TBHP in presence of $\left[\mathrm{Co}(\mathrm{acac})_{2}\right]$. Furthermore, 48a underwent aromatization with NBS and a catalytic amount of BPO to deliver phenol 51, without loss of axial integrity. After a three-step transformation, involving oxime formation, reduction, and aromatization, $\alpha$-amino atropisomeric biaryl $\mathbf{5 2}$ was prepared efficiently. A benzyl group could be installed at the $\beta$-position in $\mathbf{5 3}$ by an aldol reaction followed by oxidation. Notably, aryl iodide $\mathbf{5 4}$ could also be accessed in 75\% yield over three steps via condensation with hydrazide followed by iodization and aromatization.

\subsubsection{C-H Activation for the Synthesis of Atroposelec- tive Vinyl Arenes}

The last twenty years have witnessed important developments in $\mathrm{C}-\mathrm{H}$ activation strategies in organic synthesis. ${ }^{1 c, 18}$ Several approaches based on $\mathrm{C}-\mathrm{H}$ activation have been developed for the construction of atropisomeric styrenes.

In 2018, $\mathrm{Gu}$ and co-workers ${ }^{19}$ developed a visible-lightaccelerated stereospecific $\mathrm{C}-\mathrm{H}$ arylation for the preparation of tetrasubstituted atropisomeric vinyl arenes. The reaction was based on their previously synthesized atropisomeric vinyl arene $\mathbf{3 8}$, which reacted with diaryliodonium salts to give $\mathbf{5 6}$ without loss of enantiopurity (Scheme 10). A radical pathway was proposed on the basis of control experiments and DFT calculations. A diaryl iodine cation can be formed from diaryliodonium salts under standard conditions, which can lead to iodobenzene cationic radical INT-6 and phenyl radical INT-7 under irradiation. Radical addition to $\mathbf{3 8}$, followed by association with the palladium catalyst and $\beta-\mathrm{H}$ elimination give the final product. Kinetic studies showed that the kinetic isotope effect value changed from 3.6 in the absence of light to 1.1 on irradiation with visible light, which indicated that the $\mathrm{C}-\mathrm{H}$ functionalization step was the rate-determining step in the absence of irradiation with visible light.

Based on the $\alpha$-aryl- $\alpha, \beta$-cyclohexenone skeleton, Cui, $\mathrm{Xu}$, and co-workers ${ }^{20}$ reported an asymmetric oximedirected $\mathrm{C}-\mathrm{H}$ olefination reaction in 2018 (Scheme 11). Under $\mathrm{Pd}(\mathrm{OAc})_{2}$ catalysis, Ac-L-Ala-OH and 2-aryl cyclohex-2enone oxime ethers $\mathbf{5 7}$ were smoothly converted into atropisomeric vinyl arenes $\mathbf{5 8}$ with excellent enantioselectivity. One of the two $\mathrm{C}-\mathrm{C}$ double bonds in 58a could be selectively reduced to give $\mathbf{5 9}$ via $\mathrm{Pd} / \mathrm{C}$ catalysis under an atmosphere of hydrogen. After acting as a temporary directing group, the oxime ether group could be removed to release the 


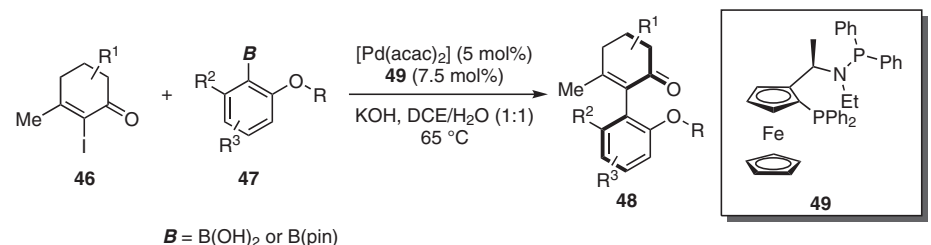

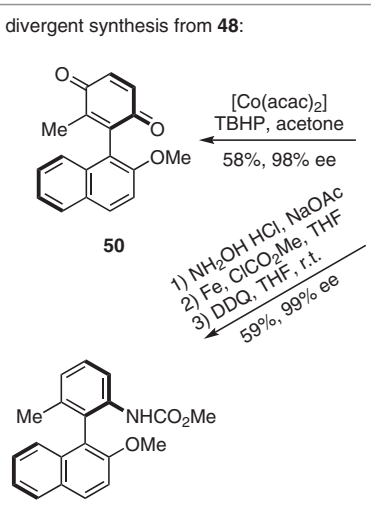

52

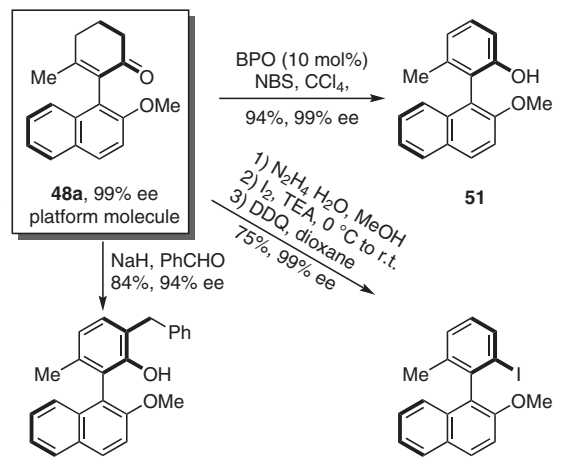

53

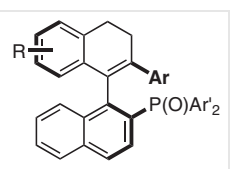

56
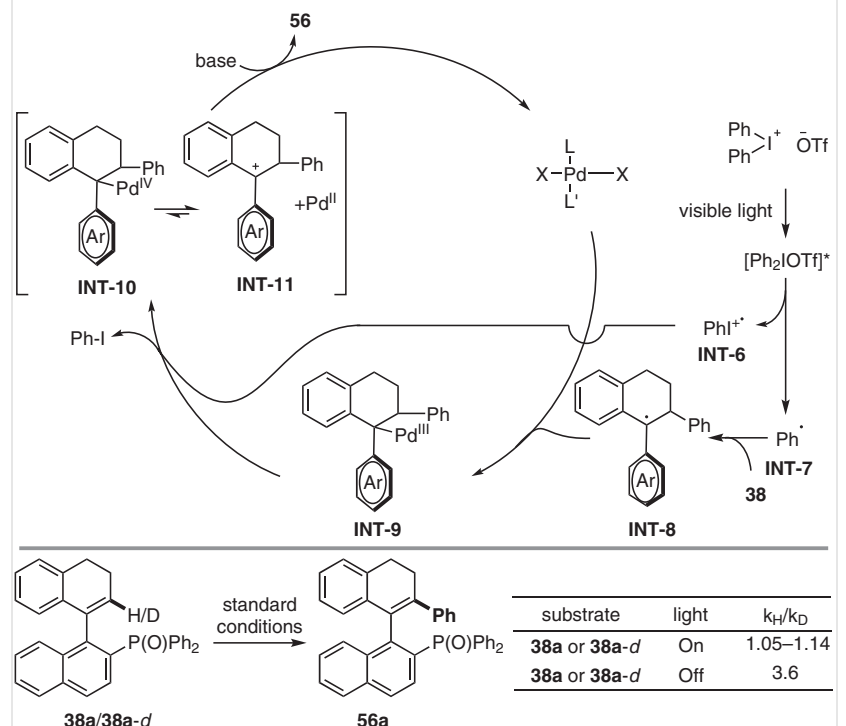

$38 \mathrm{a} / 38 \mathrm{a}-d$

$56 a$

Scheme 10 Visible-light-mediated C-H arylation

ketone group with $\mathrm{HCl}$. Diaryl phosphine $\mathbf{6 1}$ was achieved by treating $\mathbf{5 8 b}$ with diphenyl phosphorus chloride; the product was subjected to asymmetric allylation to provide $\mathbf{6 2}$ in moderate yield with $37 \%$ ee.
In 2019, Liu, Mao, and co-workers ${ }^{21}$ developed a carbopalladation and $\mathrm{C}-\mathrm{H}$ olefination for the asymmetric synthesis of atropisomeric styrenes (Scheme 12). Treatment of alkyne 63 with naphthyl iodide 64 afforded atropoactive styrene 65 featuring an oxindole scaffold with moderate enantioselectivity. In this reaction, the TADDOL-derived phosphoramidite ligand $\mathbf{6 6}$ displayed the best stereoinduction. A mechanism involving intramolecular $\mathrm{C}-\mathrm{H}$ activation was proposed. The atroposelective insertion of the $\mathrm{C} \equiv \mathrm{C}$ triple bond of $\mathbf{6 3}$ into INT-12 gave INT-13, which was regarded as the key intermediate for stereoinduction. An intramolecular C-H palladation of INT-13 formed palladacycle INT14, which delivered final product 65 and liberated $\operatorname{Pd}(0)$ after reductive elimination.

By using the concept of transient chiral auxiliaries, Shi and co-workers ${ }^{22}$ realized a palladium-catalyzed asymmetric olefination of styrene 67 in 2020 (Scheme 13). Chiral amino amide $\mathbf{7 0}$ was chosen as the optical transient chiral auxiliary, and atropisomeric styrenes $\mathbf{6 9}$ were synthesized with good yields and high stereoselectivity (up to 99\% ee). Palladacycle complex 72 was prepared by treating 71, featuring an imine moiety, with stoichiometric $\mathrm{Pd}(\mathrm{OAc})_{2}$ in $35 \%$ yield. The structure of palladium complex 72 was confirmed by single-crystal X-ray diffraction analysis. The application of $\mathbf{7 2}$ instead of $\mathrm{Pd}(\mathrm{OAc})_{2} / \mathbf{7 0}$ to the asymmetric $\mathrm{C}-\mathrm{H}$ olefination reaction under the standard conditions gave optically active 69 a with $80 \%$ ee, which indicated the possibility of an in situ formed amino amide transient directing group. The utility of the products was demonstrated by employing the corresponding $\alpha, \beta$-unsaturated chiral carboxylic acids (CCAs) as chiral ligands for the enantioselective 

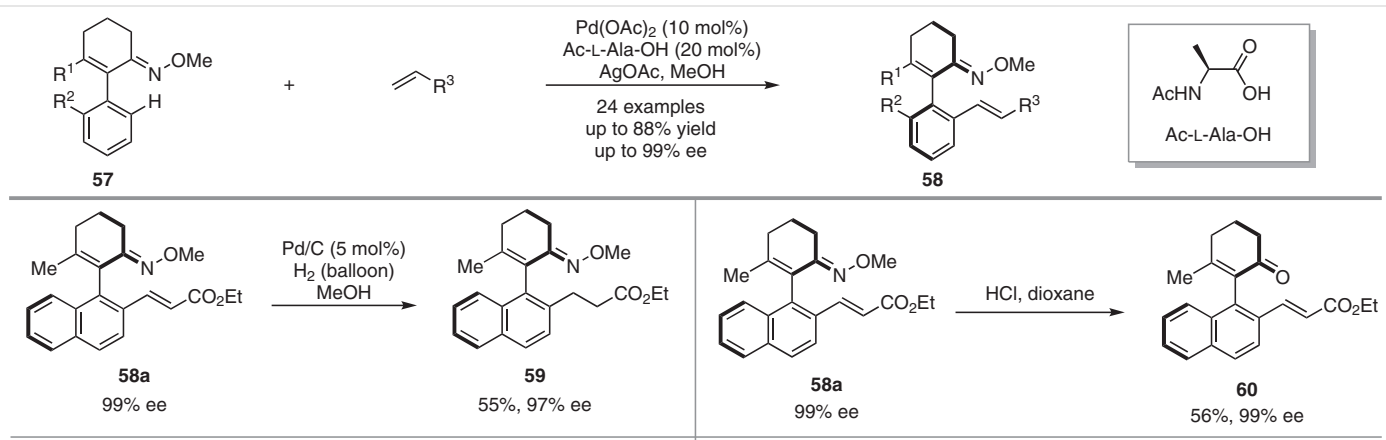

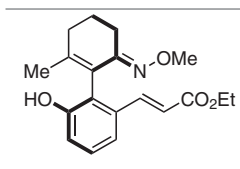

$58 b$

$96 \%$ ee

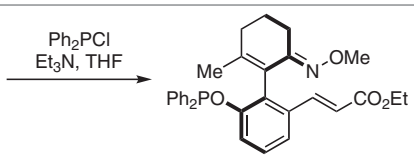

61

$52 \%, 97 \%$ ee

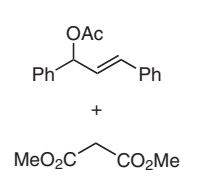

[Pd(allyl)Cl $]_{2}$ (2 mol\%)

$61(5 \mathrm{~mol} \%)$, BSA

$\stackrel{\text { CsOAc, toluene }}{\longrightarrow}$

$\mathrm{MeO}_{2} \mathrm{C} \cong \mathrm{CO}_{2} \mathrm{Me}$

$\mathrm{Ph} \overbrace{\mathrm{Ph}}$

$60 \%, 37 \%$ ee

Scheme 11 Palladium-catalyzed $\mathrm{C}-\mathrm{H}$ olefination with oxime ether as a directing group

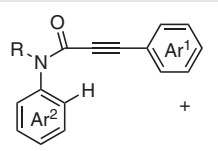

63

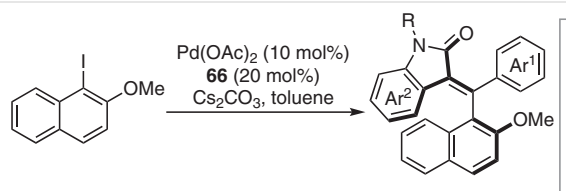

65

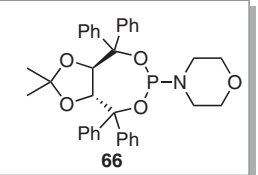

66 up to $67 \%$ ee
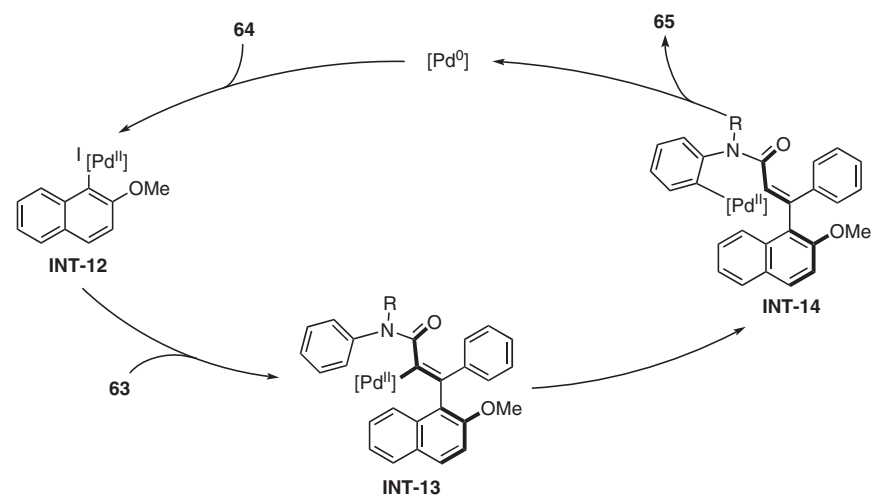

Scheme 12 Double functionalization of an alkyne

$\mathrm{C}_{\mathrm{sp} 3}-\mathrm{H}$ amidation of thioamides. In comparison with biaryl acid 75, the styrene-based acid 74 derived from 69 gave an improved enantioselectivity (from $42 \%$ ee to $64 \%$ ee).

Later, the same group ${ }^{23}$ disclosed the asymmetric synthesis of atropisomeric styrenes via $\mathrm{C}-\mathrm{H}$ alkenylation by using a 2-pyridyl moiety as a directing group (Scheme 14). The starting material $\mathbf{7 6}$ could 'freely' rotate around the vinyl-arene axis under the reaction conditions. The pyridine nitrogen atom could coordinate with palladium and the readily available L-pyroglutamic acid to form INT-15. Through good cooperation of the directing group and chiral ligand, modulation of the reactivity and induction of the stereoselectivity were achieved to give atropisomeric products 77 with good yields and enantioselectivity. The generality of substrate scope was investigated with different substituted styrenes. The reaction with alkynyl bromide was also successful, giving the coupling products with very high enantiopurity. 


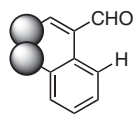

rac-67

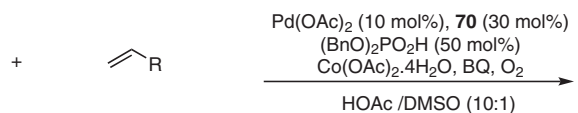

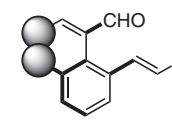

69

28 examples

up to $95 \%$ yield

up to $99 \%$ ee
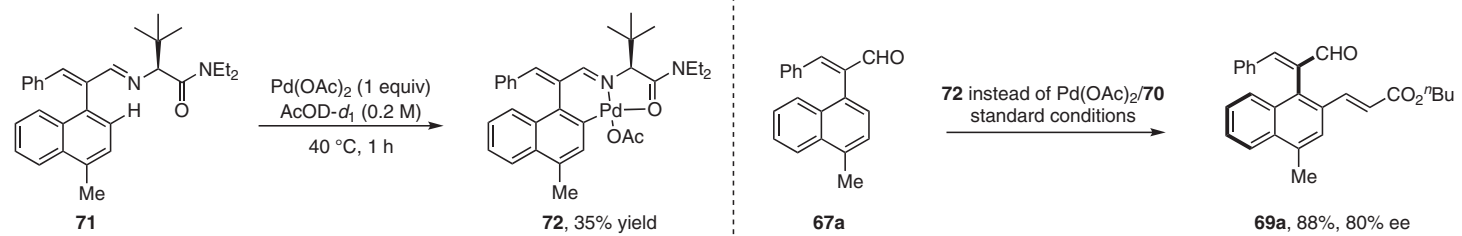

72, 35\% yield

67

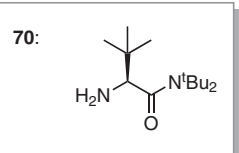

$69 a, 88 \%, 80 \%$ ee<smiles></smiles>

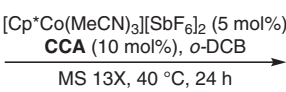

MS $13 \mathrm{X}, 40^{\circ} \mathrm{C}, 24 \mathrm{~h}$

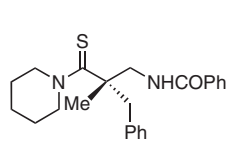

73

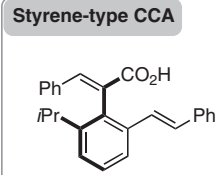

$74,73 \%, 64 \%$ ee

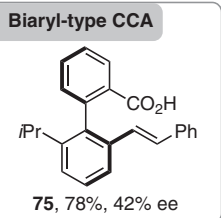

Scheme $13 \mathrm{C}-\mathrm{H}$ olefination strategy

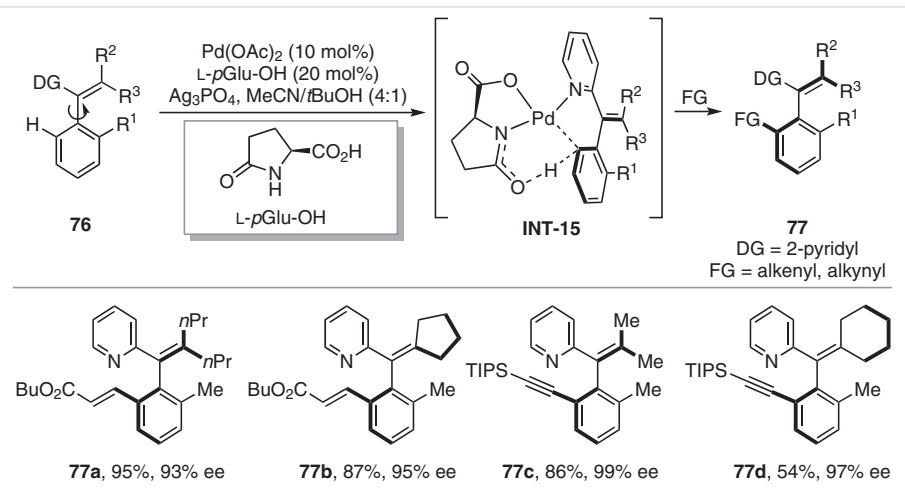

Scheme 14 Pyridine-group-directed asymmetric $\mathrm{C}-\mathrm{H}$ functionalization

Very recently, Wang and co-workers ${ }^{24}$ reported a C-H olefination and arylation for the asymmetric synthesis of atropisomeric styrenes by utilizing a carboxylic acid direction strategy (Scheme 15). The protocol demonstrated a broad substrate scope, high yields, and excellent stereoselectivity (up to 99\% ee). Notably, the absolute configuration of the products was the opposite configuration to the products of Shi and co-workers, despite Boc-L-leucine and $\mathbf{7 0}$ being derived from the same amino acid, L-leucine. The authors explained these observations by proposing two different models for the stereoinduction. In TS-1, the bulky alkyl chain of the amino acid points upward and pushes the alkenyl group away from the palladium. However, in TS-2, the upward $t \mathrm{Bu}$ group forces the alkenyl group downward, which leads to the opposite configuration. The utility of these CCAs was further demonstrated by two $\mathrm{Cp}^{*} \mathrm{Co}\left(\mathrm{CH}_{3} \mathrm{CN}\right)_{3}\left[\mathrm{SbF}_{6}\right]_{2} / \mathrm{CCA}$-catalyzed asymmetric $\mathrm{C}-\mathrm{H}$ functionalization reactions.

\subsection{Atropisomeric Synthesis of Styrenes Prompted by Nucleophilic Addition}

In 2017, Tan and co-workers ${ }^{25}$ reported an organocatalyzed atroposelective synthesis of atropisomeric styrenes by means of nucleophilic addition to propanal derivatives (Scheme 16). In the presence of chiral pyrrole 83, alkynal $\mathbf{8 1}$ was activated by forming INT-16, which underwent nucleophilic attack to generate INT-17 stereoselectively. Isomerization of INT-17 gave iminium ion INT-18, which could be converted into final product $\mathbf{8 2}$ by hydrolysis. With regard to substrate scope, styrenes bearing an iodine and sulfophenyl group (82a, 82b) could be tolerated, but installation of a methyl group at the $\alpha$-position of the axis greatly decreased the stereoselectivity to $54 \%$ ee $(\mathbf{8 2 c})$. A nucleophile containing an allyl moiety was also compatible (82d). 


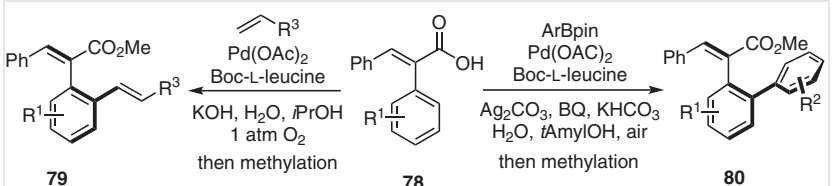

then methylation

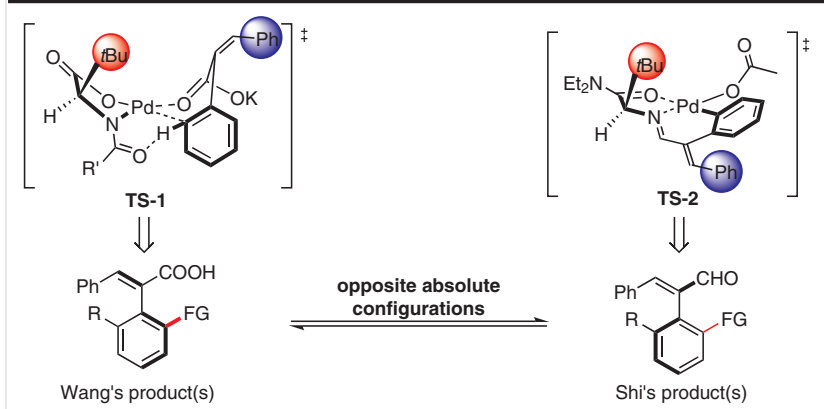

Scheme 15 Asymmetric C-H olefination and arylation with a carboxylic acid directing group

In 2018, Yan and co-workers ${ }^{26}$ described an enantioselective synthesis of sulfone-containing atropisomeric styrenes with the cooperation of quinine-derived thiourea $\mathbf{8 6}$ and L-proline (Scheme 17). A series of enantioenriched styrenes 85 was prepared with good enantioselectivity and excellent $E / Z$ selectivity by treating 1-alkynyl-naphthalen-2ols 84 with sodium sulfinates. Based on control experiments and DFT calculations, a vinylidene o-quinone methide (VQM) was proposed as the key intermediate, which significantly influenced the subsequent series of studies in this area. VQM intermediate INT-19 bears an atropisomeric allenyl moiety, which is critical for the high enantioselectivity in subsequent reactions. The activated sulfinate anion derived from the combination of L-proline and sodium sulfinate would act as a nucleophile to attack INT19, forming final product 85a. The role of boric acid was probably to release L-proline from the complex for the next catalytic cycle.

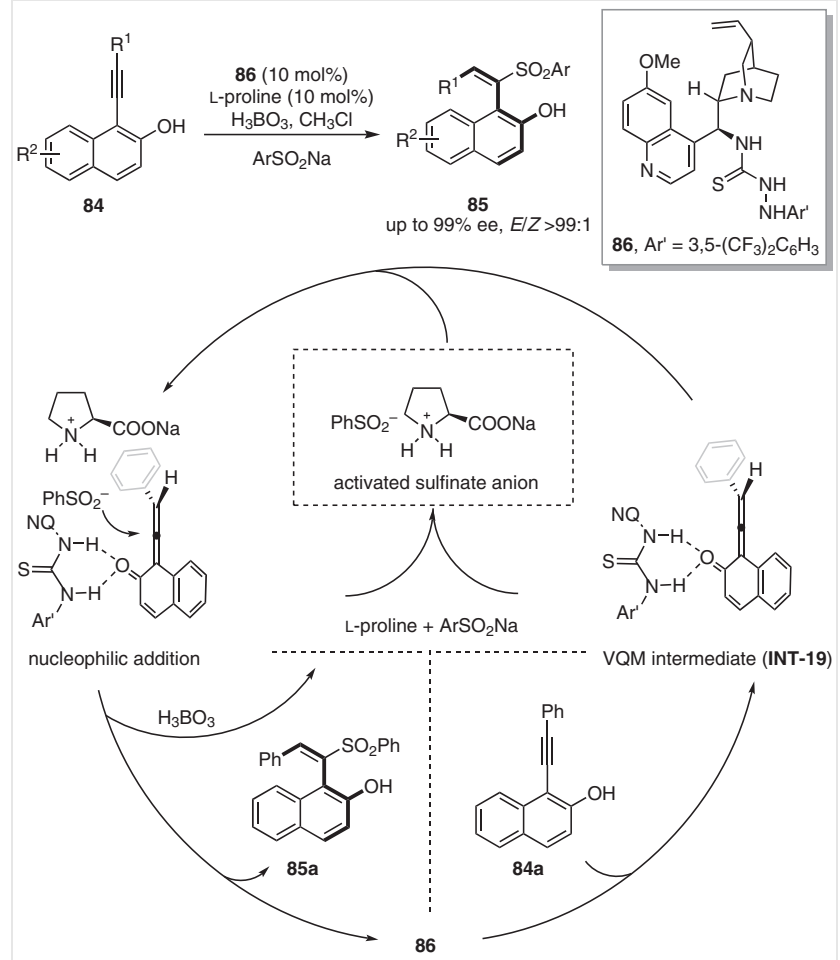

Scheme 17 Synthesis of atropisomeric styrenes via VQMs

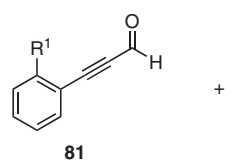

81<smiles>C(#Cc1ccccc1)C=NC1CCCC1</smiles>

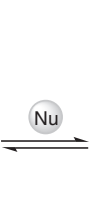

$\mathrm{Nu}$

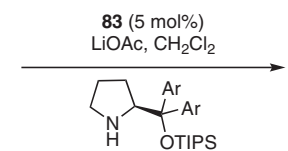

83, $\mathrm{Ar}=3,5-\mathrm{Me}_{2} \mathrm{C}_{6} \mathrm{H}_{3}$<smiles>O=C/C=C(/O)c1ccccc1</smiles>

82

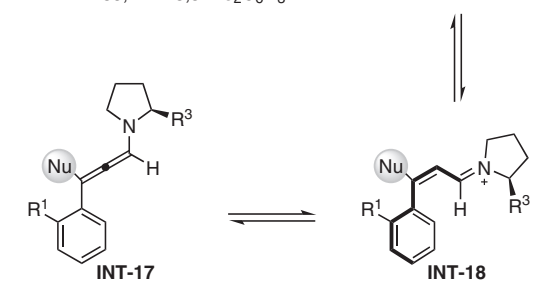

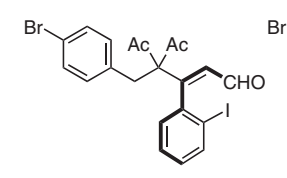

82a: $96 \%, 94 \%$ ee

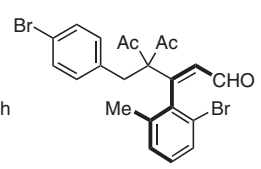

82c: $89 \%, 54 \%$ ee

82b: $40 \%, 82 \%$ ee
$(Z / E=96: 4)$

Scheme 16 Chiral pyrrole-catalyzed synthesis of chiral styrenes 
Based on the key optically active intermediate, VQM, Yan and co-workers ${ }^{27}$ completed the asymmetric synthesis of atropisomeric sulfone-containing styrenes bearing up to three axes with high enantio- and diastereoselectivities (Scheme 18a). Alkynes $\mathbf{8 7}$ reacted with arylsulfinic acid to deliver enantioenriched multi-axis styrenes $\mathbf{8 8}$ smoothly with the assistance of the chiral quinine-derived squaramide catalysts 89 via tetrasubstituted VQM INT-20. This allowed kinetic resolution with an excellent selectivity factor $(S)$. Later, the same group ${ }^{28}$ disclosed the asymmetric synthesis of atropisomeric 1,4-distyrene 2,3-naphthalene diols by means of organocatalysis (Scheme 18b). Nucleophilic addition of an amidosulfone to a VQM with the aid of cinchona squaramide $\mathbf{9 3}$ under mild reaction conditions afforded 92 featuring two chiral axes. Catalytic asymmetric synthesis of a sulfone-containing atropisomeric styrene via the Michael addition reaction of $\alpha$-amido sulfones to ynones was achieved by the same group (Scheme 18c). ${ }^{29}$ The meth- odology employed $\mathrm{N}$-squaramide $\mathbf{9 6}$ as the catalyst, giving the atropisomeric styrenes $\mathbf{9 5}$ with excellent enantioselectivity.

Benefiting from the versatile reactivity of VQM and its analogs, in 2019, Tan and co-workers ${ }^{30}$ achieved the construction of a series of disubstituted atropisomeric 1,1'(ethene-1,1-diyl)binaphthol (EBINOL) derivatives by utilizing 2-naphthol as the nucleophile (Scheme 19). Under catalysis with compound 100, atropisomeric styrenes 99 were synthesized in high yields and enantioselectivity, along with complete $E / Z$ selectivity, under mild reaction conditions. The utility of this transformation was exhibited by the preparation of atropisomeric EBINOL-based chiral phosphonic acid (ECPA) 101 and phosphoramidites 105a and $\mathbf{1 0 5 b}$. Under catalysis with 101, alkylation of indole (102) with $N$-(1-phenylvinyl)acetamide (103) afforded tertiary amine 104 smoothly with moderate enantioselectivity. By contrast, a BINOL-derived CPA gave a lower stereose-

(a)

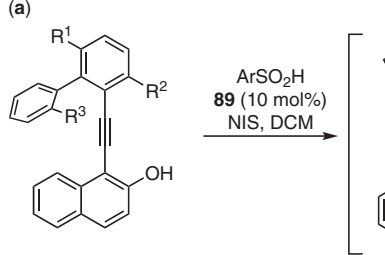

87

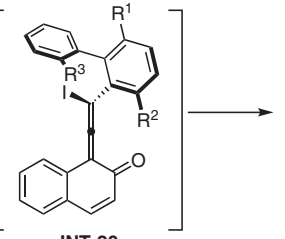

INT-20

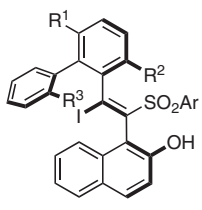

88 up to $98 \%$ ee, $E / Z>20:$ $>20: 1$ d.r.

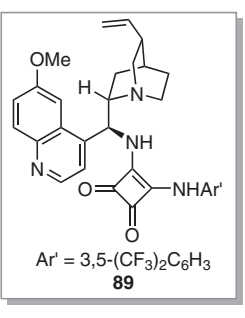

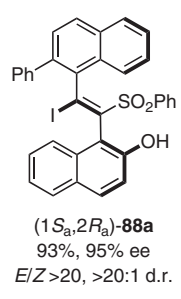
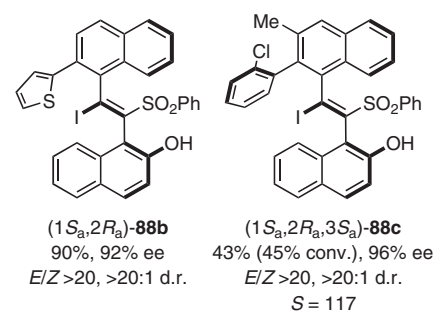

$S=117$

(b)
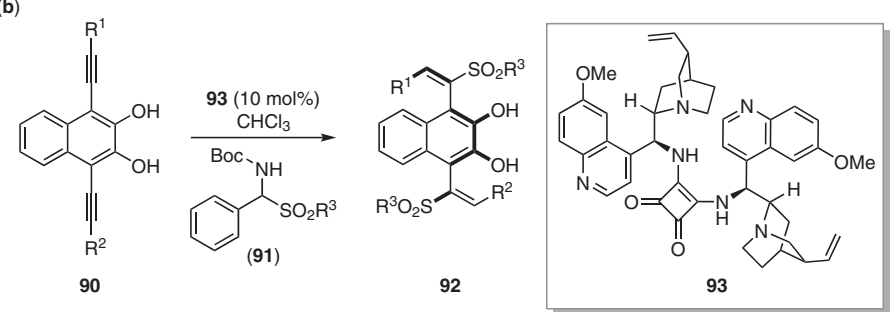

(c)

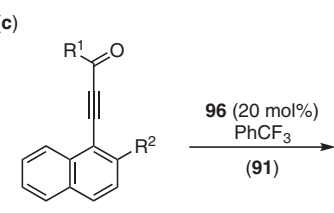

94

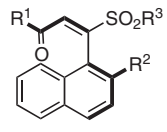

95

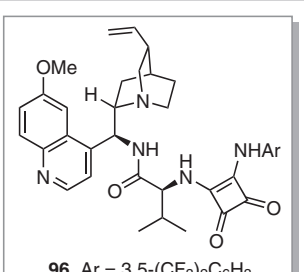

Scheme 18 Synthesis of atropisomeric styrenes via tetrasubstituted VQMs 


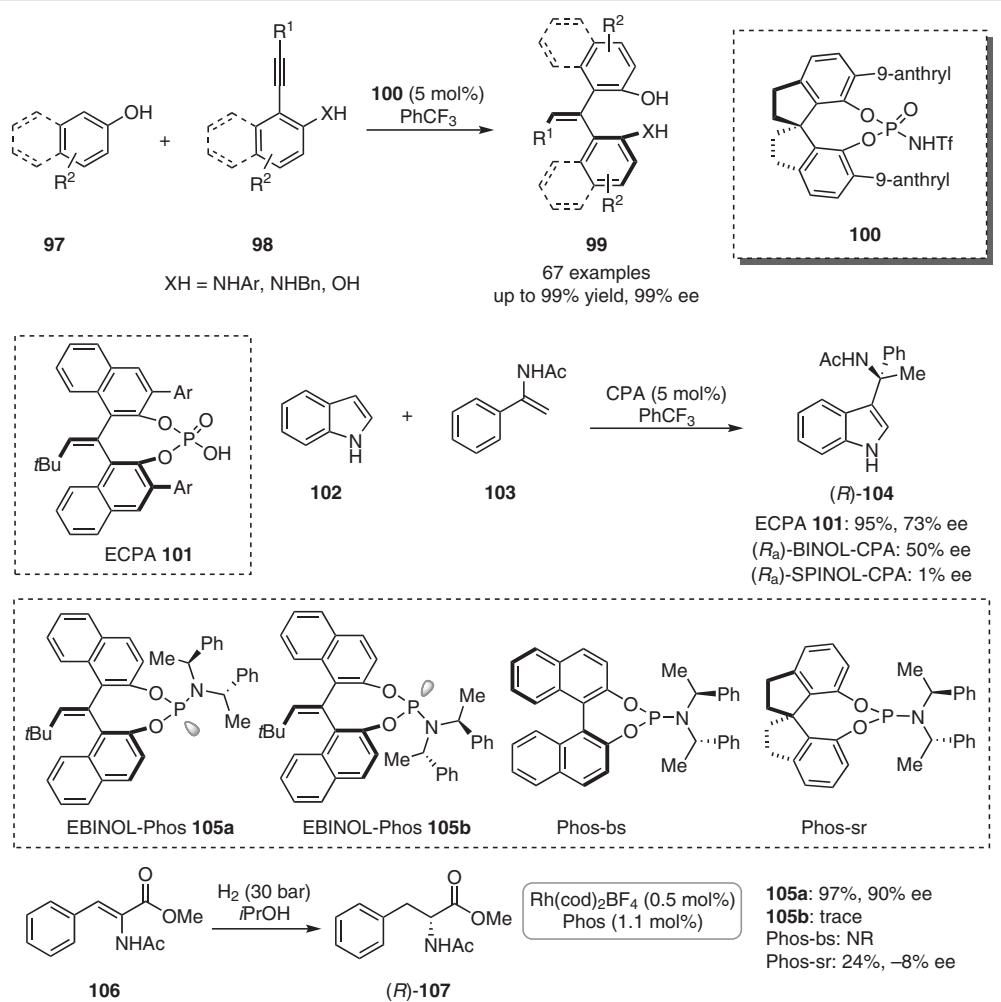

Scheme 19 Atroposelective synthesis of atropisomeric EBINOL

lectivity and a SPINOL-based CPA failed in the induction of enantioselectivity. The phosphoramidite was obtained as the pair of diastereoisomers 105a and 105b exhibiting P-stereocenters because of the lack of $\mathrm{C}_{2}$-symmetry of EBINOL. EBINOL-Phos 105a efficiently prompted the asymmetric hydrogenation of enamides $\mathbf{1 0 6}$ with $97 \%$ yield and $90 \%$ ee, whereas $\mathbf{1 0 5 b}$ afforded the product in low yield. The alternative phosphoramidites Phos-bs and Phos-sr did not give satisfactory results.
In 2020, Li, Yan, Liu, and co-workers ${ }^{31}$ applied asymmetric nucleophilic addition for the synthesis of atropisomeric styrenes bearing a stereocenter and a chiral axis (Scheme 20). Racemic 5H-oxazol-4-ones 109 worked as nucleophiles to attack the in situ formed VQM intermediate derived from 108 to afford 110 with high enantioselectivity, high diastereoselectivity, and a good $E / Z$ ratio. This method offers an efficient approach to these stereoisomers, which have potential applications in asymmetric synthesis.
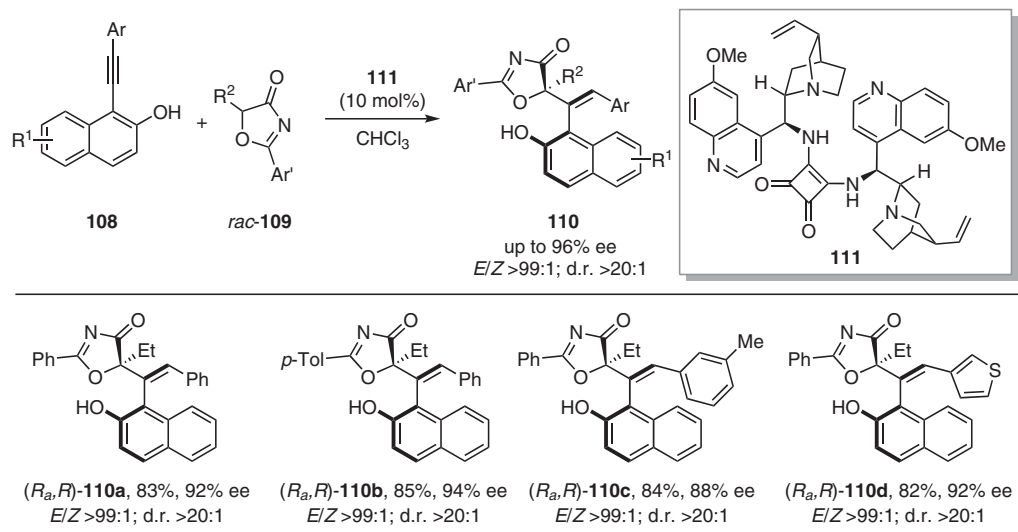

Scheme 20 Construction of atropisomeric styrenes with multiple stereoelements 

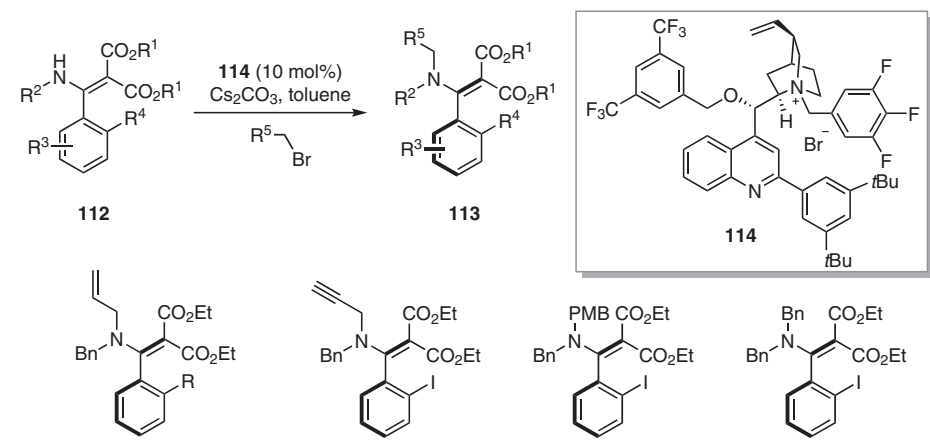

$R=1,113 a, 84 \%, 92 \%$ ee $\mathrm{R}=\mathrm{CF}_{3}, 113 \mathrm{~b}, 87 \%, 94 \%$ ee

$113 c, 91 \%, 94 \%$ ee $\quad 113 d, 76 \%, 84 \%$ ee $\quad 113 e, 65 \%, 91 \%$ ee
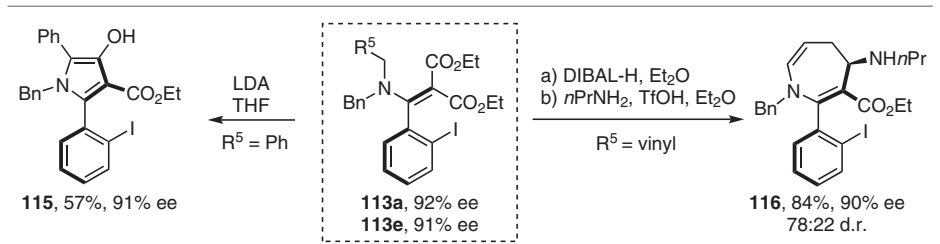

Scheme 21 Synthesis of atropisomeric styrenes via N-alkylation

N-Alkylation of enamide 112 also enabled preparation of atropisomeric styrenes. ${ }^{32}$ Nucleophilic substitution of alkyl bromides with $\mathbf{1 1 2}$ in the presence of a catalytic amount of 114 afforded enantioenriched styrenes 113 with satisfactory stereoselectivity and good functional-group tolerance (Scheme 21). Substrates including allyl bromide, propargyl bromide, 4-methoxybenzyl bromide, and benzyl bromide were successfully applied in the protocol (113a113e). A merit of this methodology was the rapid preparation of atropisomeric 2-arylpyrrole scaffold 115 by treating 113e with LDA. Atropisomer 116, featuring a seven-membered cyclic system, was also prepared by reduction of 113a with DIBAL-H followed by annulation with good enantioselectivity and 78:22 diastereoselectivity.

In 2020, Zhao and co-workers ${ }^{33}$ identified an aza-VQM as a key intermediate for the preparation of atropisomeric vinyl $\alpha$-anilines. A well-defined chiral sulfide was used as the catalyst, which promoted an asymmetric electrophilic carbothiolation and intramolecular annulation reaction (Scheme 22). INT-20 was formed by coordination of sulfur
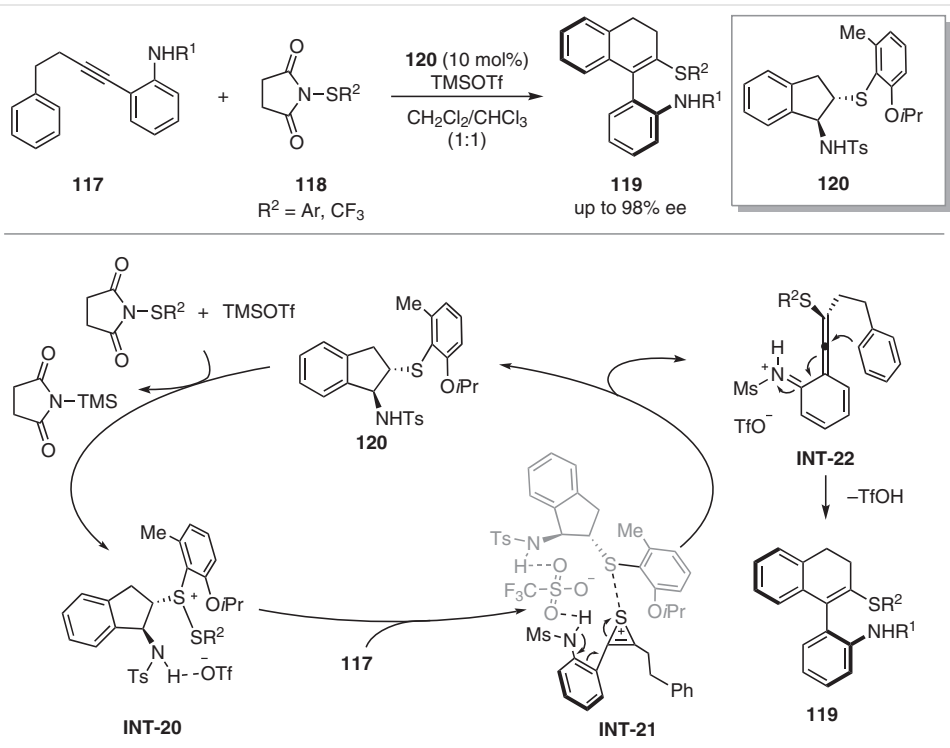

Scheme 22 Synthesis of atropisomeric styrenes via an aza-VQM intermediate 

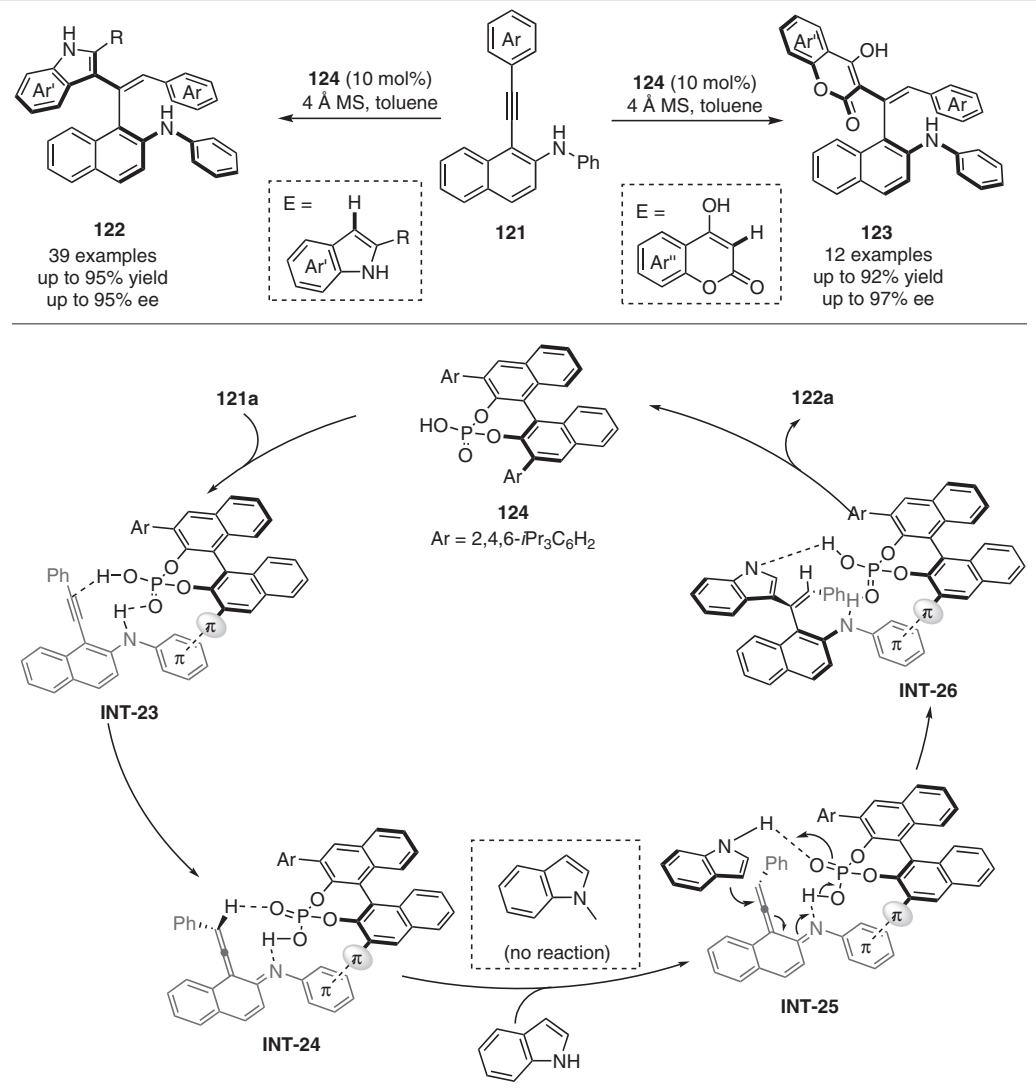

Scheme 23 Chiral phosphoric acid catalyzed atroposelective synthesis of styrenes

reagent 118 and catalyst 120 with the aid of a Lewis acid. Subsequently, INT-20 reacted with alkyne $\mathbf{1 1 7}$ to generate sulfonium salt INT-21, which transformed into aza-VQM INT-22 by elimination and liberated the catalyst. Intramolecular annulation of INT-22 afforded sulfur-containing atropisomeric styrenes 119.

Following this, Zhang and co-workers ${ }^{34}$ reported an asymmetric nucleophilic addition of 1-(ethynyl)naphthalen-2-amines to achieve a divergent synthesis of atropisomeric styrenes (Scheme 23). The reaction employed indoles or 4-hydroxycoumarins as substrates, and high yields and excellent enantioselectivity were obtained. Based on previous work and control experiments, a mechanism involving a $\pi-\pi$ interaction and hydrogen-bond-mediated model was proposed. Combination of 121a with chiral phosphoric acid 124 would generate INT-23, which could isomerize to azaVQM INT-24 in an enantioselective form. INT-24 could then be attacked by the indole to give INT-26. Subsequent dissociation of INT-26 would afford enantioenriched 122a and regenerate $\mathbf{1 2 4}$. The hydrogen bond plays a vital role in the reactivity and enantiocontrol. By contrast, $N$-methyl indole displayed no selectivity under identical conditions.
An atropisomeric styrene framework bearing a novel seven-membered bridged ring was also synthesized by Shi and co-workers in 2020 (Scheme 24)..$^{35}$ (3-Alkynyl-2-indolyl)methanols 125 can readily generate optically active allenes with the assistance of chiral phosphorous acid 127, which was atroposelectively attacked by 2-naphthol to give acyclic chiral styrenes. Intramolecular dehydration afforded the fused atropisomeric styrene $\mathbf{1 2 6}$.

Later, the same group ${ }^{36}$ reported a kinetic resolution of indole-based vinyl aniline $\mathbf{1 2 8}$ (Scheme 25). The resolution, featuring a high selectivity factor $(S)$, allowed efficient control of conversion and enantioselectivity and offered an approach to a new class of atropisomeric styrenes.

\subsection{Asymmetric Phase-Transfer Alkylation}

Enolization of 3,4-dihydronaphthalen-2(1H)-one gives a 3,4-dihydronaphthalen-2-ol intermediate. In 2017, Smith and co-workers ${ }^{37}$ realized an asymmetric 0 -alkylation strategy for the atroposelective synthesis of atropisomeric styrenes via chiral phase-transfer catalysis (Scheme 26). The methodology employed ketone $\mathbf{1 3 2}$ as the enolate precursor. O-Alkylation with the assistance of chiral ammoni- 
<smiles>Oc1ccc2cc(-c3ccccc3)ccc2c1</smiles>

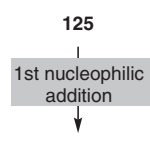

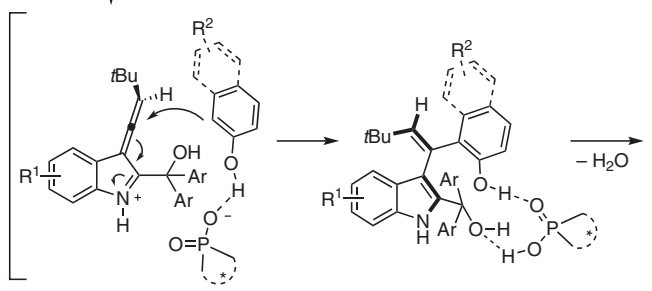<smiles>Oc1cc2c3c(c1O)CCCC3CC2</smiles><smiles>COc1cc2c3c(c1)OCCCCC3CCC2</smiles>
127, $G=2$-naphthyl

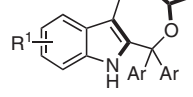

$$
126
$$

2nd nucleophilic addition

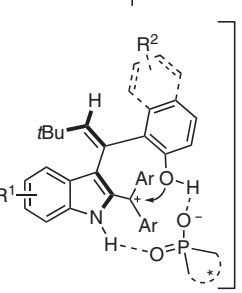

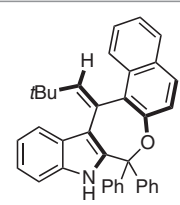

126a, $97 \%, 95 \%$ ee $E / Z>95: 5$

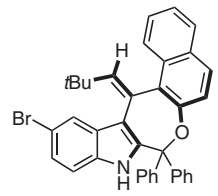

126b, $87 \%, 91 \%$ ee $E / Z>95: 5$

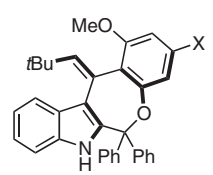

$X=C l, 126 c, 60 \%, 91 \%$ ee, $E / Z>95: 5$ $X=B r, 126 d, 61 \%, 94 \%$ ee, $E / Z>95: 5$

Scheme 24 Atropisomeric styrene synthesis from 3-alkynyl-2-indolylmethanols

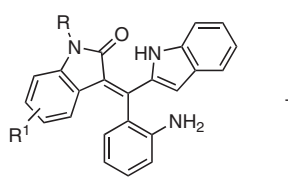

rac-128

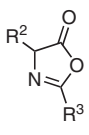

129

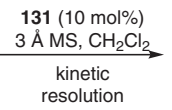

resolution

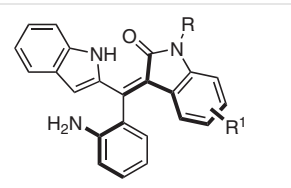

$\left(R_{a}\right)-128$

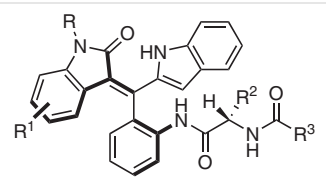

$\left(S_{a}, S\right)-130$

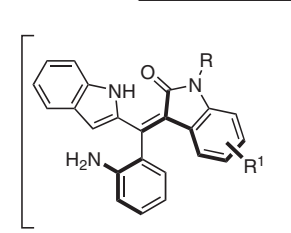

$\left(R_{a}\right)-128$

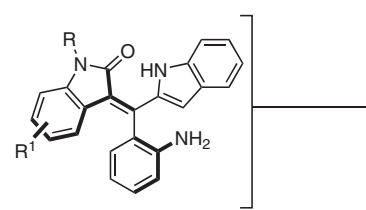

$\left(S_{a}\right)-128$

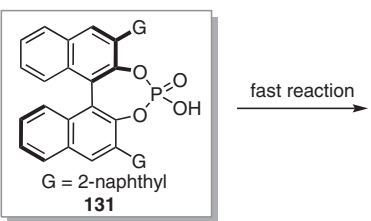

131
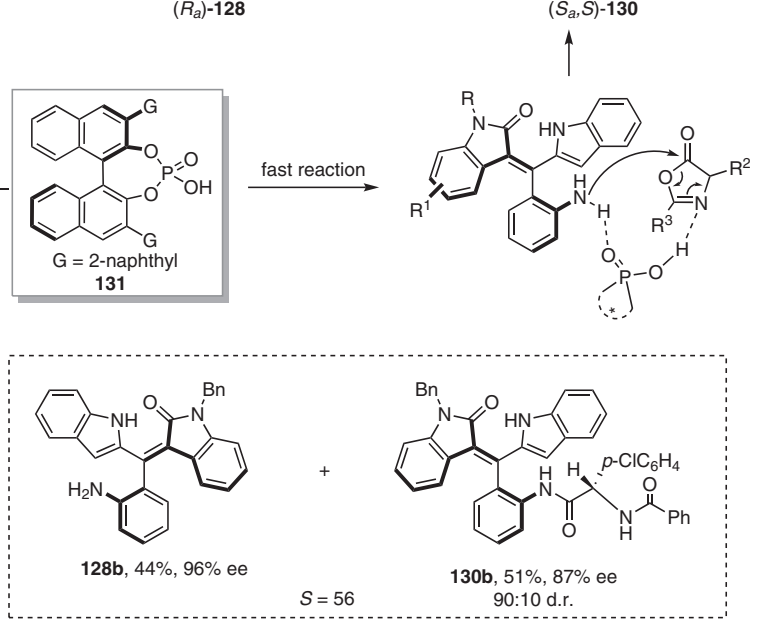

Scheme 25 Catalytic kinetic resolution

um salt 134 afforded enol ether 133 with excellent enantioselectivity. The procedure commenced with racemic ketone 132, featuring central chirality, as the substrate; this could generate the enolate with the aid of solid potassium phosphate and coordinate with the chiral ammonium salt to afford soluble diastereoselective ion pairs INT-27 and INT-28. The diastereomers bearing atropisomeric information could interconvert through protonation and deprotonation. Atropisomeric styrene 133a was exposed to $m$-chloroperoxybenzoic acid to afford the corresponding epoxide, 


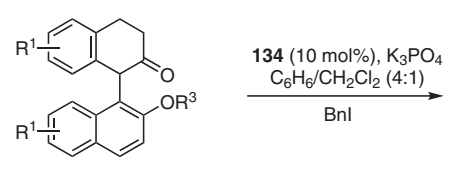

132
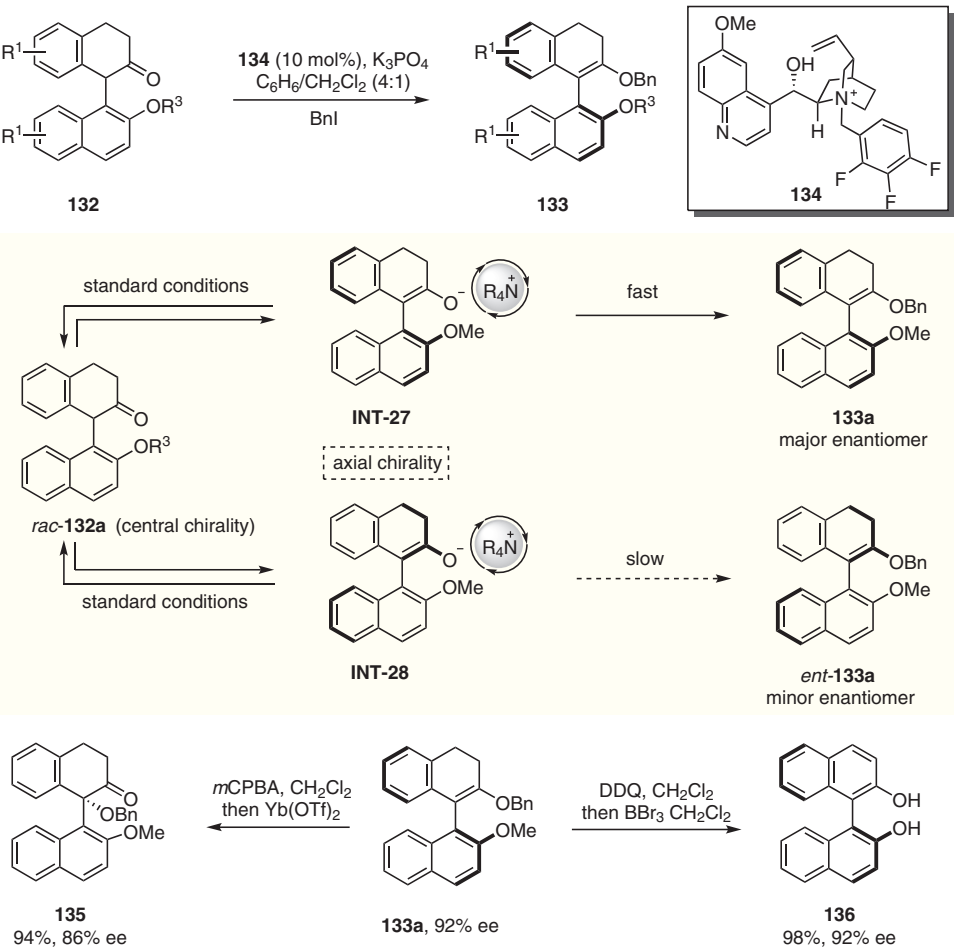

$133 a, 92 \%$ ee

Scheme 26 Asymmetric O-alkylation

which was subsequently rearranged with catalytic ytterbium triflate to give 135 with central chirality. BINOL 136 was obtained readily by oxidation and dealkylation of 133a without erosion of enantioselectivity.

\section{Stability of the Chirality of Atropisomeric Styrenes}

In comparison with biaryl atropisomers, atropisomeric styrenes display less stability because of their less rigid skeleton. The numbers and size of adjacent substituents can dramatically affect the rotational barriers of styrenes. Although no bridged atropisomeric styrenes have been discussed in the literature, fused molecules with appropriate ring sizes showed excellent stability. Of course, the influence of the $Z / E$ geometry of the $C=C$ double on the stability of the chiral axis cannot be ruled out. In early studies, compound 2 was not resolvable because of the low steric hinderance of the hydrogen atom. Nevertheless, enantiomers of compound $\mathbf{5}$, bearing an isopropyl moiety at the $\alpha$-position, could be separated by resolution. In the research of Adams and co-workers, ${ }^{6,7}(E)$-137 with a carboxylic acid as the adjacent group could be resolved, whereas the axis of (Z)-138 could rotate freely at room temperature with hydrogen as the adjacent substituent (Figure 2).

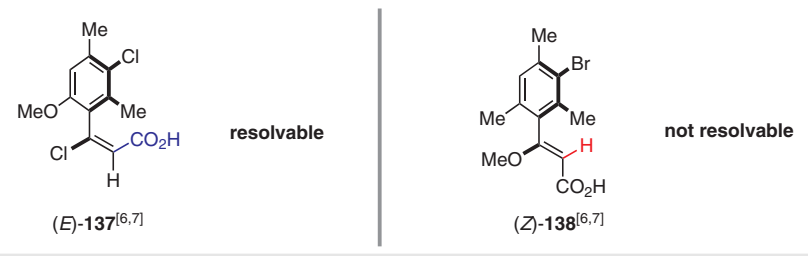

Figure 2 Geometric effects on the stability of atropisomers

In accordance with racemization experiments and DFT calculations, atropisomeric styrenes with suitable substituents have been synthesized and used as novel framework ligands or bioactive compounds. In Figure 3, the reported data for the rotational barriers of some atropisomeric styrenes are depicted to demonstrate their structure-stability relationships. It is foreseeable that the number and steric size of the substituents next to the axis will significantly affect the rotational barriers of these atropisomers. Currently, it is hard to draw the conclusion that dihydro-binaphthalene and $1-(1 H$-inden-3-yl $)$ naphthalene structures have higher chiral stabilities than the corresponding acyclic atropisomeric styrenes. 

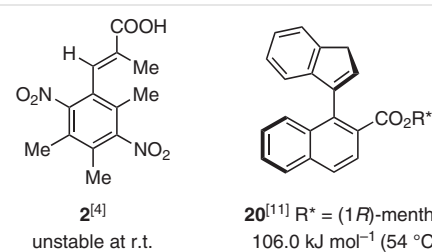

$20^{[11]} \mathrm{R}^{\star}=(1 R)$-menthyl $106.0 \mathrm{~kJ} \mathrm{~mol}^{-1}\left(54^{\circ} \mathrm{C}\right)$
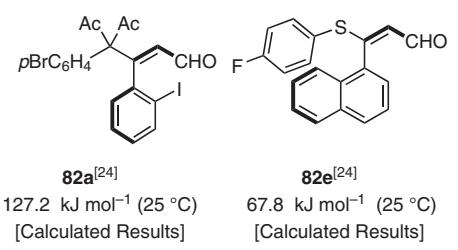

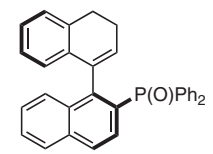

$38 \mathrm{a}^{[18]}$

$120.1 \mathrm{~kJ} \mathrm{~mol}^{-1}\left(80^{\circ} \mathrm{C}\right) \quad 115.5 \mathrm{~kJ} \mathrm{~mol}^{-1}\left(100^{\circ} \mathrm{C}\right)$
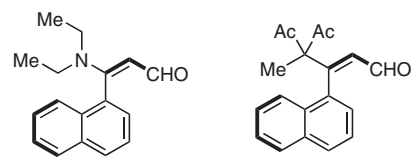

$\mathbf{8 2 f}^{[24]}$
$123.1 \mathrm{~kJ} \mathrm{~mol}^{-1}\left(25^{\circ} \mathrm{C}\right)$
$[$ Calculated Results]

$82 \mathbf{g}^{[24]}$

$106.3 \mathrm{~kJ} \mathrm{~mol}^{-1}\left(25^{\circ} \mathrm{C}\right)$

[Calculated Results]

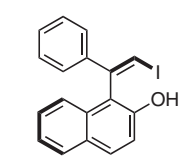

$139^{[24]}$ $122.2 \mathrm{~kJ} \mathrm{~mol}^{-1}\left(25^{\circ} \mathrm{C}\right)$ [Calculated Results]

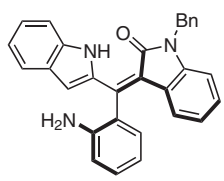

$128 \mathrm{a}^{[34]}$ $114.0 \mathrm{~kJ} \mathrm{~mol}^{-1}\left(80^{\circ} \mathrm{C}\right)$

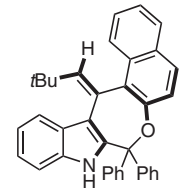

$126 \mathrm{a}^{[33]}$

$117.2 \mathrm{~kJ} \mathrm{~mol}^{-1}\left(60^{\circ} \mathrm{C}\right)$

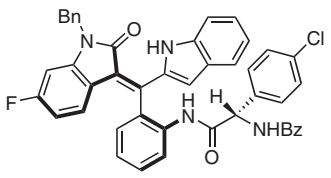

$130 \mathrm{c}^{[34]}$

$124.4 \mathrm{~kJ} \mathrm{~mol}^{-1}\left(100^{\circ} \mathrm{C}\right)$

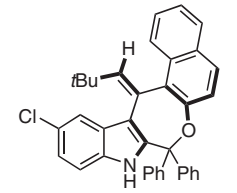

$126 \mathrm{e}^{[33]}$

$117.2 \mathrm{~kJ} \mathrm{~mol}^{-1}\left(60^{\circ} \mathrm{C}\right)$

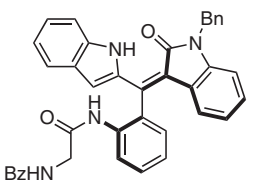

$140^{[34]}$

$119.6 \mathrm{~kJ} \mathrm{~mol}^{-1}\left(80^{\circ} \mathrm{C}\right)$

Figure 3 Rotational barriers

\section{Outlook}

Atropisomeric styrenes bearing a $\mathrm{C}(\text { vinyl })_{\mathrm{sp} 2}-\mathrm{C}(\operatorname{aryl})_{\mathrm{sp} 2}$ bond as the rotation-restricted axis have been overlooked for decades because of their relatively lower rotation barriers in comparison with those of their biaryl counterparts. Much effort has been devoted to exploiting approaches for the synthesis of stable atropisomeric styrenes in the last ten years. Many novel styrene frameworks have been constructed, demonstrating unique applications in asymmetric synthesis. However, new methodologies for the efficient, practical asymmetric synthesis of atropisomeric styrenes with high enantioselectivity are still desirable.

\section{Conflict of Interest}

The authors declare no conflict of interest.

\section{Funding Information}

This work was supported by the National Natural Science Foundation of China (21901236, 21871241).

\section{References}

(1) (a) Bao, X.; Rodriguez, J.; Bonne, D. Angew. Chem. Int. Ed. 2020 , 59, 12623. (b) Toenjes, S. T.; Gustafson, J. L. Future Med. Chem. 2018, 10, 409. (c) Liao, G.; Zhou, T.; Yao, Q. J.; Shi, B. F. Chem. Commun. 2019, 55, 8514.

(2) (a) Shan, G.; Flegel, J.; Li, H.; Merten, C.; Ziegler, S.; Antonchick, A. P.; Waldmann, H. Angew. Chem. Int. Ed. 2018, 57, 14250. (b) Wang, F.; Qi, Z.; Zhao, Y.; Zhai, S.; Zheng, G.; Mi, R.; Huang, Z.; Zhu, X.; He, X.; Li, X. Angew. Chem. Int. Ed. 2020, 59, 13288. (c) Zhu, S.; Chen, Y. H.; Wang, Y. B.; Yu, P.; Li, S. Y.; Xiang, S. H.; Wang, J. Q.; Xiao, J.; Tan, B. Nat. Commun. 2019, 10, 4268.

(3) Hyde, J. F.; Adams, R. J. Am. Chem. Soc. 1928, 50, 2499.

(4) Maxwell, R. W.; Adams, R. J. Am. Chem. Soc. 1930, 52, 2959.

(5) Mills, W. H.; Dazeley, G. H. J. Chem. Soc. 1939, 460.

(6) Adams, R.; Miller, M. W. J. Am. Chem. Soc. 1940, 62, 53.

(7) (a) Adams, R.; Anderson, A. W.; Miller, M. W. J. Am. Chem. Soc. 1941, 63, 1589. (b) Adams, R.; Binder, L. O. J. Am. Chem. Soc. 1941, 63, 2773. (c) Adams, R.; Gross, W. J.J. Am. Chem. Soc. 1942, 64, 1786. (d) Adams, R.; Binder, L. O.; McGrew, F. C. J. Am. Chem. Soc. 1942, 64, 1791. (e) Adams, R.; Miller, M. W.; McGrew, F. C.; Anderson, A. W. J. Am. Chem. Soc. 1942, 64, 1795. (f) Adams, R.; Theobold, C. W. J. Am. Chem. Soc. 1943, 65, 2383. (g) Adams, R.; Ludington, R. S. J. Am. Chem. Soc. 1945, 67, 794. (h) Adams, R.; Mecorney, J. W. J. Am. Chem. Soc. 1945, 67, 798. 
(8) Kawabata, T.; Yahiro, K.; Fuji, K. J. Am. Chem. Soc. 1991, 113, 9694.

(9) Roselló, J. M.; Staniland, S.; Turner, N. J.; Clayden, J. Tetrahedron 2016, 72, 5172.

(10) Hattori, T.; Date, M.; Sakurai, K.; Morohashi, N.; Kosugib, H.; Miyano, S. Tetrahedron Lett. 2001, 42, 8035.

(11) Baker, R. W.; Hambley, T. W.; Turner, P.; Wallace, B. J. Chem. Commun. 1996, 2571.

(12) Mori, K.; Ohmori, K.; Suzuki, K. Angew. Chem. Int. Ed. 2009, 48, 5633.

(13) Mori, K.; Ohmori, K.; Suzuki, K. Angew. Chem. Int. Ed. 2009, 48, 5638.

(14) (a) Schmitz, P.; Malter, M.; Lorscheider, G.; Schreiner, C.; Carboni, A.; Choppin, S.; Colobert, F.; Speicher, A. Tetrahedron 2016, 72, 5230. (b) Meidlinger, D.; Marx, L.; Bordeianu, C.; Choppin, S.; Colobert, F.; Speicher, A. Angew. Chem. Int. Ed. 2018, 57, 9160. (c) Xi, J.; Gu, Z. Chin. J. Chem. 2020, 38, 1081.

(15) Feng, J.; Li, B.; He, Y.; Gu, Z. Angew. Chem. Int. Ed. 2016, 55, 2186.

(16) Wu, H.; Han, Z.; Qu, B.; Wang, D.; Zhang, Y.; Xu, Y.; Grinberg, N.; Lee, H.; Song, J.; Roschangar, F.; Wang, G.; Senanayake, C. Adv. Syn. Catal. 2017, 359, 3927.

(17) Pan, C.; Zhu, Z.; Zhang, M.; Gu, Z. Angew. Chem. Int. Ed. 2017, 56, 4777.

(18) Colobert, F.; Wencel-Delord, J. SynOpen 2020, 4, 107.

(19) Feng, J.; Li, B.; Jiang, J.; Zhang, M.; Ouyang, W.; Li, C.; Fu, Y.; Gu, Z. Chin. J. Chem. 2018, 36, 11.

(20) Sun, Q. Y.; Ma, W. Y.; Yang, K. F.; Cao, J.; Zheng, Z. J.; Xu, Z.; Cui, Y. M.; Xu, L. W. Chem. Commun. 2018, 54, 10706.

(21) Yang, Y.; Liu, H.; Liu, X.; Liu, T.; Zhu, Y.; Zhang, A.; Wang, T.; Hua, Y.; Wang, M.; Mao, G.; Liu, L. Chin. J. Org. Chem. 2019, 39, 1655.

(22) Song, H.; Li, Y.; Yao, Q. J.; Jin, L.; Liu, L.; Liu, Y. H.; Shi, B. F. Angew. Chem. Int. Ed. 2020, 59, 6576.
(23) Jin, L.; Yao, Q.-J.; Xie, P.-P.; Li, Y.; Zhan, B.-B.; Han, Y.-Q.; Hong, X.; Shi, B.-F. Chem 2020, 6, 497.

(24) Yang, C.; Wu, T.-R.; Wu, B.-B.; Li, Y.; Jin, R.; Hu, D.-D.; Li, Y.-B.; Bian, K.-J.; Wang, X.-S. Chem. Sci. 2021, DOI: in press; 10.1039/D0SC06661C

(25) Zheng, S. C.; Wu, S.; Zhou, Q.; Chung, L. W.; Ye, L.; Tan, B. Nat. Commun. 2017, 8, 15238.

(26) Jia, S.; Chen, Z.; Zhang, N.; Tan, Y.; Liu, Y.; Deng, J.; Yan, H. J. Am. Chem. Soc. 2018, 140, 7056.

(27) Tan, Y.; Jia, S.; Hu, F.; Liu, Y.; Peng, L.; Li, D.; Yan, H. J. Am. Chem. Soc. 2018, 140, 16893.

(28) Li, S.; Xu, D.; Hu, F.; Li, D.; Qin, W.; Yan, H. Org. Lett. 2018, 20, 7665.

(29) Zhang, N.; He, T.; Liu, Y.; Li, S.; Tan, Y.; Peng, L.; Li, D.; Shan, C.; Yan, H. Org. Chem. Front. 2019, 6, 451.

(30) Wang, Y.-B.; Yu, P.; Zhou, Z.-P.; Zhang, J.; Wang, J.; Luo, S.-H.; Gu, Q.-S.; Houk, K. N.; Tan, B. Nat. Catal. 2019, 2, 504.

(31) Huang, A.; Zhang, L.; Li, D.; Liu, Y.; Yan, H.; Li, W. Org. Lett. 2019 , $21,95$.

(32) Wang, Y.-B.; Wu, Q.-H.; Zhou, Z.-P.; Xiang, S.-H.; Cui, Y.; Yu, P.; Tan, B. Angew. Chem. Int. Ed. 2019, 58, 13443.

(33) Liang, Y.; Ji, J.; Zhang, X.; Jiang, Q.; Luo, J.; Zhao, X. Angew. Chem. Int. Ed. 2020, 59, 4959.

(34) Li, Q. Z.; Lian, P. F.; Tan, F. X.; Zhu, G. D.; Chen, C.; Hao, Y.; Jiang, W.; Wang, X. H.; Zhou, J.; Zhang, S. Y. Org. Lett. 2020, 22, 2448.

(35) Wang, C. S.; Li, T. Z.; Liu, S. J.; Zhang, Y. C.; Deng, S.; Jiao, Y.; Shi, F. Chin. J. Chem. 2020, 38, 543.

(36) Ma, C.; Sheng, F. T.; Wang, H. Q.; Deng, S.; Zhang, Y. C.; Jiao, Y.; Tan, W.; Shi, F. J. Am. Chem. Soc. 2020, 142, 15686.

(37) Jolliffe, J. D.; Armstrong, R. J.; Smith, M. D. Nat. Chem. 2017, 9, 558. 